\title{
Optical properties of Saharan dust aerosol and contribution from the coarse mode as measured during the Fennec 2011 aircraft campaign
}

\author{
C. L. Ryder ${ }^{1}$, E. J. Highwood ${ }^{1}$, P. D. Rosenberg ${ }^{2}$, J. Trembath ${ }^{3}$, J. K. Brooke ${ }^{2}$, M. Bart ${ }^{2}{ }^{*}$, A. Dean ${ }^{3}$, J. Crosier ${ }^{4}$, \\ J. Dorsey ${ }^{4}$, H. Brindley ${ }^{5}$, J. Banks ${ }^{5}$, J. H. Marsham ${ }^{6}$, J. B. McQuaid ${ }^{2}$, H. Sodemann ${ }^{7}$, and R. Washington ${ }^{8}$ \\ ${ }^{1}$ Department of Meteorology, University of Reading, RG6 6BB, Reading UK \\ ${ }^{2}$ School of Earth and Environment, University of Leeds, LS2 9JT, Leeds, UK \\ ${ }^{3}$ Facility for Airborne Atmospheric Measurements, Cranfield, UK \\ ${ }^{4}$ School of Earth, Atmospheric and Environmental Sciences, University of Manchester, Manchester, UK \\ ${ }^{5}$ Space and Atmospheric Physics, Department of Physics, Imperial College, London, UK \\ ${ }^{6}$ National Centre for Atmospheric Science, University of Leeds, Leeds, UK \\ ${ }^{7}$ Institute for Atmospheric and Climate Science, ETH Zürich, Switzerland \\ ${ }^{8}$ Department of Geography, University of Oxford, Oxford, UK \\ *now at: Aeroqual Ltd, 109 Valley Road, Auckland, New Zealand
}

Correspondence to: C. L. Ryder (c.1.ryder@reading.ac.uk)

Received: 20 September 2012 - Published in Atmos. Chem. Phys. Discuss.: 11 October 2012

Revised: 19 December 2012 - Accepted: 23 December 2012 - Published: 11 January 2013

\begin{abstract}
New in-situ aircraft measurements of Saharan dust originating from Mali, Mauritania and Algeria taken during the Fennec 2011 aircraft campaign over a remote part of the Sahara Desert are presented. Size distributions extending to $300 \mu \mathrm{m}$ are shown, representing measurements extending further into the coarse mode than previously published for airborne Saharan dust. A significant coarse mode was present in the size distribution measurements with effective diameter $\left(d_{\text {eff }}\right)$ from 2.3 to $19.4 \mu \mathrm{m}$ and coarse mode volume median diameter $\left(d_{\mathrm{vc}}\right)$ from 5.8 to $45.3 \mu \mathrm{m}$. The mean size distribution had a larger relative proportion of coarse mode particles than previous aircraft measurements. The largest particles (with $d_{\text {eff }}>12 \mu \mathrm{m}$, or $d_{\mathrm{vc}}>25 \mu \mathrm{m}$ ) were only encountered within $1 \mathrm{~km}$ of the ground. Number concentration, mass loading and extinction coefficient showed inverse relationships to dust age since uplift. Dust particle size showed a weak exponential relationship to dust age. Two cases of freshly uplifted dust showed quite different characteristics of size distribution and number concentration.

Single Scattering Albed (SSA) values at $550 \mathrm{~nm}$ calculated from the measured size distributions revealed high absorption ranging from 0.70 to 0.97 depending on the refractive
\end{abstract}

index. SSA was found to be strongly related to $d_{\text {eff. New }}$ instrumentation revealed that direct measurements, behind Rosemount inlets, overestimate SSA by up to 0.11 when $d_{\text {eff }}$ is greater than $2 \mu \mathrm{m}$. This is caused by aircraft inlet inefficiencies and sampling losses. Previous measurements of SSA from aircraft measurements may also have been overestimates for this reason. Radiative transfer calculations indicate that the range of SSAs during Fennec 2011 can lead to underestimates in shortwave atmospheric heating rates by 2.0 to 3.0 times if the coarse mode is neglected. This will have an impact on Saharan atmospheric dynamics and circulation, which should be taken into account by numerical weather prediction and climate models.

\section{Introduction}

The Sahara is the world's largest dust source (Washington et al., 2003; Shao et al., 2011) Here, dust is uplifted by strong near-surface winds and transported to high altitudes by deep boundary layer convection (Cuesta et al., 2009), and then typically transported westwards within the Saharan Air Layer 
Table 1. Major aircraft measurement campaigns in recent years measuring Saharan mineral dust, in chronological order.

\begin{tabular}{|c|c|c|c|c|c|}
\hline Campaign Name & Acronym & Date & Base Location & Flight Region Sampled & Reference \\
\hline Puerto Rico Dust Experiment & PRIDE & Jun/Jul 2000 & Puerto Rico & western Atlantic & Reid and Maring (2003) \\
\hline SaHAran Dust Experiment & SHADE & Sep 2000 & Cape Verde & eastern Atlantic & Haywood et al. (2003) \\
\hline Dust And Biomass burning Experiment & DABEX & Jan 2006 & Niamey & southern Sahara & Haywood et al. (2008) \\
\hline $\begin{array}{l}\text { Dust Outflow and Deposition to the } \\
\text { Ocean } 1 \text { and } 2\end{array}$ & DODO1, DODO2 & Feb \& Aug 2006 & Dakar & $\begin{array}{l}\text { eastern Atlantic \& } \\
\text { western Mauritania }\end{array}$ & McConnell et al. (2008) \\
\hline Saharan Mineral Dust Experiment 1 & SAMUM-1 & May/Jun 2006 & Ouarzazate & southern Morocco & Heintzenberg (2009) \\
\hline African Monsoon Multidisciplinary Analysis & AMMA & Jun, Jul, Aug 2006 & Niamey & Sahel/southern Sahara & Redelsperger et al. (2006) \\
\hline NASA-AMMA & NAMMA & Aug 2006 & Cape Verde & eastern Atlantic & Chen et al. (2011) \\
\hline Geostationary Earth Radiation Budget & GERBILS & Jun 2007 & Niamey/Nouakchott & southern Sahara & Haywood et al. (2011) \\
\hline \multicolumn{6}{|l|}{$\begin{array}{l}\text { Intercomparison of Longwave and } \\
\text { Shortwave radiation }\end{array}$} \\
\hline Saharan Mineral Dust Experiment 2 & SAMUM-2 & Jan 2008 & Cape Verde & eastern Atlantic & Ansmann et al. (2011) \\
\hline Fennec 2011 & & Jun 2011 & Canary Islands & Mauritania and Mali & Washington et al. (2013) \\
\hline
\end{tabular}

(SAL) during summer, and deposited to the Atlantic Ocean (Karyampudi et al., 1999). During this lifecycle dust plays an important role in climate through a variety of mechanisms. It is able to alter the atmospheric radiation balance by interacting with both long and shortwave (terrestrial and solar) radiation. This process also has the ability to affect the dynamics of the atmosphere through radiative absorption and heating, and by decreasing surface temperatures over land and ocean. This can affect model accuracy over regions with large dust loadings (Haywood et al., 2005; Lavaysse et al., 2011) and also have an impact on sea surface temperatures (Highwood et al., 2003). Saharan dust also has the potential to affect tropical cyclone development by modifying sea surface temperatures (Evan et al., 2008), by intensifying the stability of the Saharan Air Layer through atmospheric heating (Dunion and Velden, 2004), and by acting as ice nuclei (Richardson et al., 2007). Finally dust is deposited to the ocean, supplying nutrients and affecting biogeochemical cycles (Jickells et al., 2005).

Given the potential impacts, an accurate understanding of properties such as the vertical distribution, size distribution and optical properties of dust are vital, not least for use in and evaluation of weather and climate models. For example, in climate models, size distributions affect the distance over which dust is transported and the rate of deposition, and therefore its effect on climate such as atmospheric circulation, surface air temperature and precipitation (Ackerley et al., 2012; Perlwitz and Miller, 2010). The deposition of bioavailable iron to the oceans by dust in climate models is sensitive to particle size distribution (Ito et al., 2012). Finally, the radiative effect of dust is strongly dependent on the coarse mode size distribution as the larger particles appreciably lower the single scattering albedo (SSA, or $\left.\omega_{0}\right)$, (McConnell et al., 2010; Otto et al., 2009). Despite this, most weather and climate models use relatively high SSA values (Forster et al., 2007) and generally represent size distributions only up to $10 \mu \mathrm{m}$ diameter (Huneeus et al., 2011). Recent work (Kok (2011a)) shows that differences in size distributions between climate models and observations result in top of atmosphere radiative forcing differences of a factor of 2 to 15 .

Due to the remoteness of the Sahara, plentiful and regular in-situ measurements of airborne dust are not available. However, several aircraft campaigns over recent years have attempted to measure the properties of Saharan mineral dust in remote regions or downwind of them, and have made significant progress in the understanding of dust microphysical and optical properties. Table 1 provides details of the major aircraft campaigns and associated acronyms which have taken place since 2000 with a focus on in-situ dust measurements. Of the listed experiments, AMMA, DABEX, a few flights from DODO, SAMUM-1 and GERBILS made intensive measurements over the Sahara, while the majority of DODO, SAMUM-2 and NAMMA measured dust over the eastern Atlantic Ocean. PRIDE measured dust transported across the Atlantic. Of the land-bound flights, SAMUM-1 was based in southern Morocco and the GERBILS, AMMA and DABEX flights were located at around $18^{\circ} \mathrm{N}$ or further south. Thus measuring the properties of dust over a vast area of the central Sahara using in-situ airborne measurements has yet to be achieved, and the Fennec campaign represents significant advances by providing new measurements close to dust sources over the remote Sahara.

In addition to the challenge of measuring dust in remote locations comes the difficulty of measuring coarse particles on aircraft. Previous aircraft measurements have recorded very different descriptions of the coarse mode, and it is not always clear whether these differences are due to instrumental and sampling differences, or due to the different geographical measurement location and dust event types. For example, far larger coarse mode was measured in SAMUM1 than in GERBILS (Johnson and Osborne, 2011). Analysis by Weinzierl et al. (2011) of SAMUM-2 measurements over the ocean found less coarse mode present, and attributed the large SAMUM-1 presence of coarse particles to the close proximity to dust sources. Explicitly, they found that during SAMUM-1 particles larger than $30 \mu \mathrm{m}$ were found in $51 \%$ of cases, whereas particles larger than $30 \mu \mathrm{m}$ were not observed at all during SAMUM-2 over the ocean. Earlier campaigns 
struggled to measure the coarse mode effectively - for example Haywood et al. (2003) used AERosol RObotic NETwork (AERONET) retrievals to constrain the coarse mode size distribution during SHADE (above $3 \mu \mathrm{m}$ ), which in themselves may suffer from problems such as underestimating the coarse mode (Müller et al., 2010, 2012). DABEX coarse mode measurements were taken inside the aircraft by a PCASP-X sampling through a CVI with appreciable amounts of pipework which would entail loss of the majority of the coarse particles (Osborne et al., 2008). During AMMA, airborne OPC size distributions of up to $2 \mu \mathrm{m}$ measured behind an inlet with $50 \%$ efficiency at $4 \mu \mathrm{m}$ diameter have been presented by Matsuki et al. (2010), and Formenti et al. (2011a) present measurements up to $20 \mu \mathrm{m}$ nominal diameter made behind an isokinetic inlet with a $50 \%$ passing efficiency at $9 \mu \mathrm{m}$ diameter. Coarse mode measurements up to $40 \mu \mathrm{m}$ were only operational on a few flights during DODO (McConnell et al., 2008). Particles up to diameters of 18 and $5 \mu \mathrm{m}$ were measured during PRIDE and NAMMA respectively (Reid et al., 2003; Chen et al., 2011). Consistent measurements of coarse mode during SAMUM and GERBILS (up to $30 \mu \mathrm{m}$ ) represent important advances, but further measurements of coarse particles at altitude over desert areas are required to improve our understanding of the sensitivity to measurement technique and geographical variability, and to link these to optical properties of dust (Ansmann et al., 2011).

Direct measurements of scattering and absorption also suffer from the difficulty of measuring the coarse mode on aircraft, since the optical properties of dust are strongly dependent on the amount of coarse mode present (McConnell et al., 2008). Whereas it is possible to measure size distributions on wing-mounted probes, scattering and absorption instrumentation are typically located inside aircraft cabins, and this therefore subjects these measurements to modification by aircraft inlets and loss through pipework. For example, on the UK's BAe-146-301 Large Atmospheric Research Aircraft operated by the Facility for Airborne Atmospheric Measurements (henceforth the FAAM aircraft), scattering and absorption measurements are made behind Rosemount inlets. Previously it has been considered likely that these inlets pass only particles smaller than around $2 \mu \mathrm{m}$ diameter (Haywood et al., 2003), but this has never been directly quantified. Absorption measurements on the DLR Falcon aircraft, though behind a different type of inlet, suffer from the same problem and represent only diameters smaller than $3 \mu \mathrm{m}$ (Petzold et al., 2011). Absorption and scattering measurements of this type produce measurements of single scattering albedo (Haywood et al., 2003; Osborne et al., 2008; McConnell et al., 2008; Johnson et al., 2011; Johnson and Osborne, 2011), which among other uses inform climate models, and further information such as refractive indices can be derived from them (Petzold et al., 2009; McConnell et al., 2010). Despite this, measurements of this type are limited to representing the aerosol accumulation mode, a significant limitation for min- eral dust measurements when considering possible impacts on atmospheric dynamics and model validation.

The Fennec project (Washington et al., 2013) was designed to better understand the Saharan climate system through targeted ground observations (Marsham et al., 2013; Todd et al., 2013; Hobby et al., 2012), aircraft measurements (McQuaid et al., 2013) and remote sensing (Banks and Brindley, 2013) over the remote Sahara in 2011 and 2012. Here we present in-situ aircraft measurements of Saharan dust from the Fennec June 2011 campaign over previously unsampled regions of Mauritania and Mali, and aim to provide a better understanding of the nature and importance of coarse dust particles. Particle size distributions, and their variability due to altitude, dust age and dust event type will be presented. The associated optical properties are described, and the extent to which previous aircraft measurements may have underestimated the amount of absorption attributed to dust by being unable to measure the coarse mode effectively will be explored.

Section 2 describes the flight patterns performed, the instrumentation used, and the methods applied to the measurements to determine optical properties. Section 3 presents results of the measured size distributions, Sect. 4 presents the optical properties associated with the size distributions, Sect. 5 explores the potential factors influencing the particle size and optical properties, Section 6 describes their impact on atmospheric heating rates and Sect. 7 concludes the article.

\section{Method}

\subsection{Flight patterns and data selection}

During June 2011 the FAAM aircraft conducted 16 dedicated flights over Mauritania and Mali, sampling Saharan dust whenever the aircraft flew within the Saharan boundary layer. A full description of flight patterns and aircraft instrumentation during Fennec is presented in McQuaid et al. (2013) Here we present results from 11 flights where the FAAM aircraft made in-situ measurements of dust with consistent instrumentation. Brief details of these flights are shown in Table 2.

Flights where in-situ measurements were made consisted of two main aircraft manoeuvres: straight and level runs (henceforth referred to as horizontal legs), where the aircraft flew at a fixed altitude or pressure level, and profiles. Horizontal legs provide detailed information on dust properties and spatial variability at a particular altitude, whereas the profiles provide an insight into the vertical structure of the dust layer. This article presents data from horizontal legs only - further studies will examine vertical profiles, as the interpretation of profiles is complicated by both horizontal and vertical structures contributing to the observed variation. 


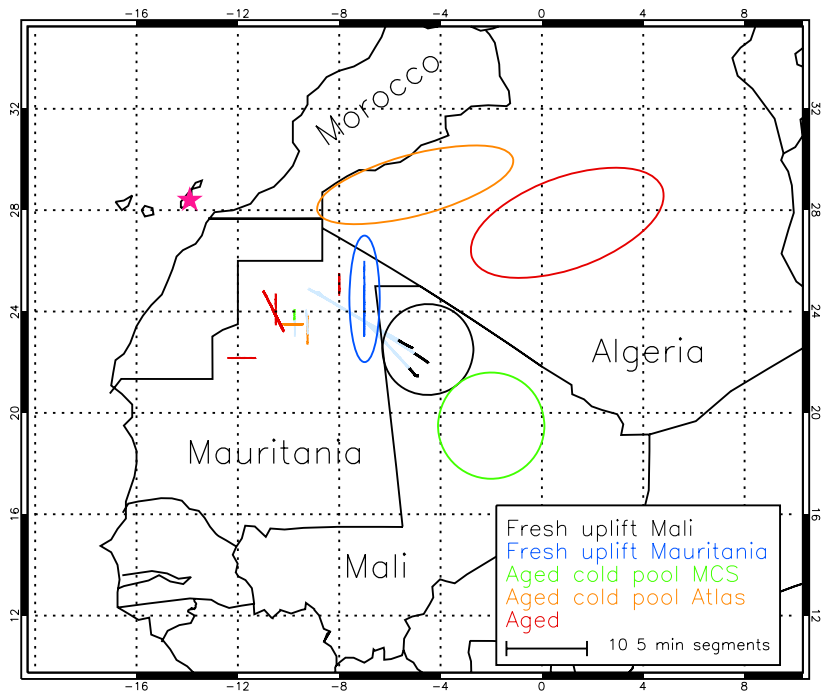

Fig. 1. Map showing locations of in-situ measurements and dust source regions. Straight lines show locations of in-situ straight and level runs (horizontal legs) used in this study. Circles indicate likely source areas of the dust sampled during the flights. Pink star indicates the location of Fuerteventura, Canary Islands, Spain, where the FAAM aircraft was based. Different colors correspond to the event categories described in Sect. 5 and Fig. 11. Horizontal legs in grey are not included in Fig. 11.

Horizontal legs were typically aimed at in-situ sampling, and therefore tended to be at low altitudes where dust loadings were highest (see Fig. 2). We use pressure height as a metric which is available throughout all the flights, but note that pressure height can differ somewhat from altitude above ground, particularly at lower altitudes and over orography. Figure $2 \mathrm{~b}$ shows a histogram of altitude above ground for the horizontal legs examined here, which come from the aircraft radar and are available beneath $2.4 \mathrm{~km}$ above ground. Around $50 \%$ of horizontal legs analysed here come from measurements at heights beneath $100 \mathrm{~m}$ of ground level.

A threshold scattering of $10 \mathrm{Mm}^{-1}$ has been used as a criterion to eliminate horizontal legs with very low amounts of aerosol. Horizontal legs lasted between 5 min and two hours, therefore data have been averaged over 5 min segments for analysis, which each cover around $35 \mathrm{~km}$. This resulted in a total of 117 segments for analysis. Locations of these 117 segments are shown in Fig. 1, and their respective altitude distribution in Fig. 2. Note that the $35 \mathrm{~km}$ segments appear rather small in Fig. 1 due to the large area covered by the map.

Throughout the article, we refer to optical properties at $550 \mathrm{~nm}$ wavelength, unless specified otherwise. All references to particle size refer to diameter. The term "accumulation mode" is used for particles with diameters smaller than $3 \mu \mathrm{m}$, and "coarse mode" for particles larger than this. The prefix $s$ (e.g. $\left.\mathrm{scm}^{-3}\right)$ is used to indicate the provision of mea-
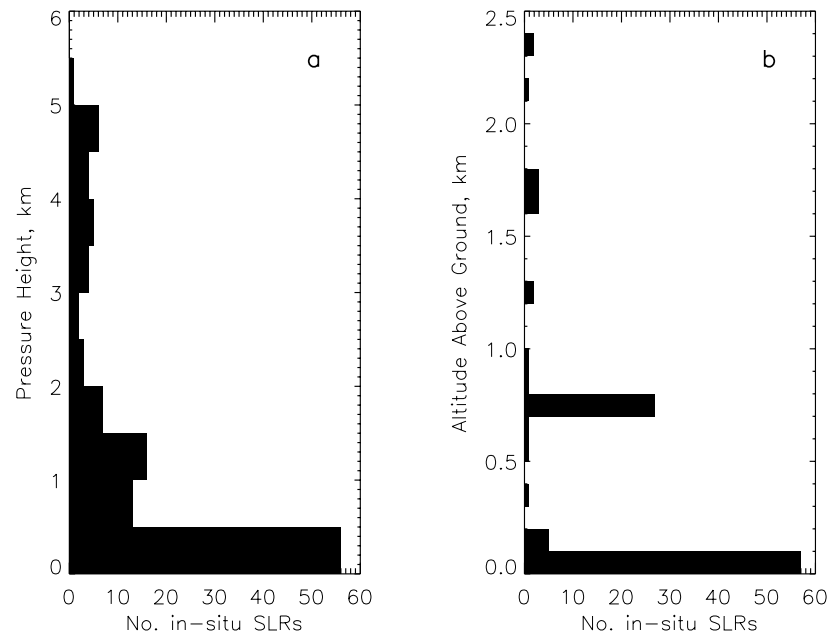

Fig. 2. (a) Histogram of altitudes (in pressure height) of in-situ horizontal legs; (b) histogram of altitude above ground of horizontal legs from the aircraft radar, where data is available at altitudes lower than $2.4 \mathrm{~km}$ above the ground surface (subsample of pressure heights beneath $2.4 \mathrm{~km}$ from (a)).

Table 2. Dates and times of flights used in this study. Full details can be found in McQuaid et al. (2013)

\begin{tabular}{llll}
\hline $\begin{array}{l}\text { Number } \\
\text { Flight }\end{array}$ & Date & $\begin{array}{l}\text { Times of in-situ } \\
\text { measurements, UTC }\end{array}$ & $\begin{array}{l}\text { Color in } \\
\text { Fig. 1 }\end{array}$ \\
\hline b600 & 17 June 2011 & 10:00 to 11:15 & black \\
b601 & 17 June 2011 & 17:15 to 18:15 & black \\
b602 & 18 June 2011 & $10: 15$ to $11: 30$ & black \\
b604 & 20 June 2011 & $15: 15$ to $15: 45$ & green \\
b605 & 21 June 2011 & $10: 00$ to $10: 30$ & orange \\
b606 & 21 June 2011 & $16: 00$ to $18: 00$ & orange \\
b609 & 24 June 2011 & $13: 30$ to $14: 40$ & red \\
b610 & 25 June 2011 & $09: 15$ to $10: 45$ & blue \\
b611 & 25 June 2011 & $16: 30$ to $17: 30$ & red \\
b612 & 26 June 2011 & $09: 30$ to $10: 45$ & red \\
b613 & 26 June 2011 & $15: 45$ to 18:00 & red \\
\hline
\end{tabular}

surements at standard temperature and pressure, otherwise measurements are ambient.

\subsection{Instrumentation}

A full description of the aircraft instrumentation during Fennec is given in McQuaid et al. (2013). Further details regarding instruments relevant to this article are summarised in Table 3 and described below.

\subsubsection{Size distribution measurements}

Size distributions covering 0.1 to $930 \mu \mathrm{m}$ nominal diameters were measured using optical and light shadowing techniques (see Table 3), where nominal refers to the diameter supplied by the instrument manufacturer. Accumulation mode 


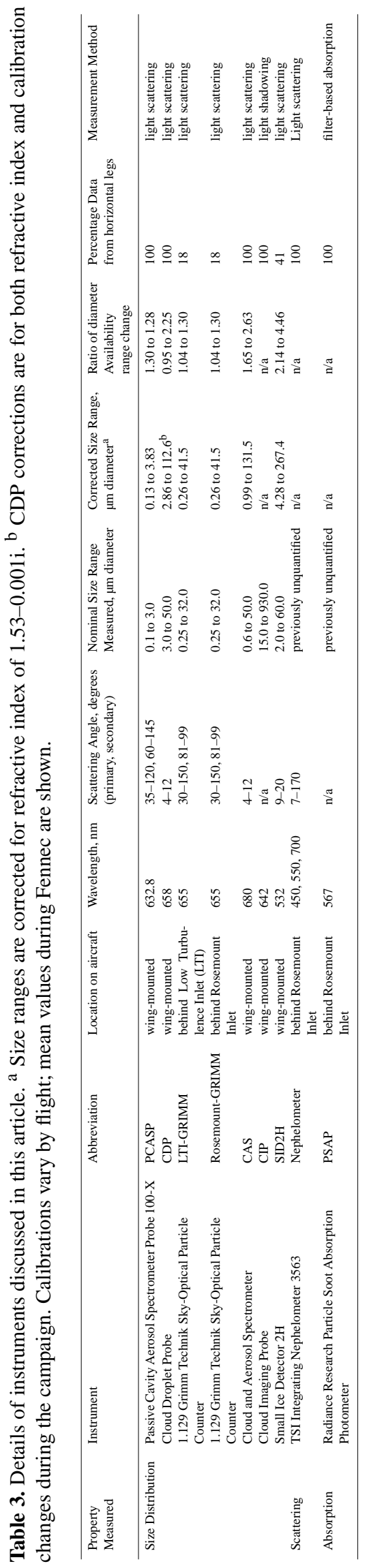


particles were measured by a wing-mounted Passive Cavity Aerosol Spectrometer Probe 100X (PCASP, 0.1-3.0 $\mu \mathrm{m}$ ). Coarse mode particles were measured by a Cloud Droplet Probe (CDP, 2-50 $\mu \mathrm{m}$ ), a Small Ice Detector 2H (SID2H, 2$60 \mu \mathrm{m}$, Cotton et al. (2010)), a Cloud and Aerosol Spectrom-

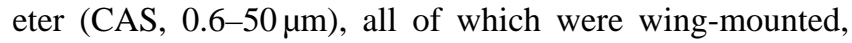
and finally by a Grimm Technik 1.129 Sky Optical Particle Counter (OPC, Heim et al. (2008)) mounted inside the aircraft cabin behind a Low Turbulence Inlet (LTI-GRIMM, $0.25-32 \mu \mathrm{m})$. Giant particles were measured by a wingmounted Cloud Imaging Probe (CIP) covering 15 to $930 \mu \mathrm{m}$. The CAS and CIP are part of a Cloud, Aerosol and Precipitation Spectrometer (CAPS, Baumgardner et al., 2001).

Of particular interest during Fennec was the use of four different instruments on the FAAM aircraft for the first time covering the coarse mode size range of around 2 to $30 \mu \mathrm{m}$ nominal diameter. This duplication provides increased confidence in the coarse mode size distributions and useful information concerning the relative performance of the different instruments. Rosenberg et al. (2012) describe the calibrations and corrections performed on the PCASP and CDP during Fennec, and only a brief summary is provided here. These calibration and correction procedures were also applied to the SID2H.

The PCASP was calibrated before Fennec. Rosenberg et al. (2012) note that the scattering cross sections defining the bin edges differed by up to $33 \%$ from those provided by the manufacturer during Fennec, even before refractive index size corrections were performed. The PCASP suffered from problems at the boundaries of gain stages affecting bins 5 and 6 , and 15 and 16 . Therefore the number concentrations for these two sets of bins were merged, resulting in slightly wider size bins (before refractive index correction was performed). Bin 30 was also removed from the data for this reason.

The CDP was cleaned and calibrated as described in Rosenberg et al. (2012) seven times during Fennec due to the possibility of dust dirtying the instrument and extreme heat cycling affecting the optical alignment. This also allows any drift with time in the size of the bins to be monitored and accounted for. Rosenberg et al. (2012) report that during Fennec the nominal bin boundaries were consistently higher than those defined by the manufacturer, particularly for the smallest size bins. Additionally, the width of the first size bin was set much wider than usual which increases the CDP's sensitivity to smaller particles. This first bin has been split into 5 smaller bins to give additional information on this part of the size distribution. This results in the minimum (refractive index corrected) particle size measured by the CDP decreasing from 3.0 to $2.19 \mu \mathrm{m}$ (see Table 3), although the maximum size range measured increases by up to a factor of 3 due to refractive index corrections (see Sect. 2.3).

Monitoring the changes in the size ranges measured enables more accurate measurements of the ambient size distributions, and therefore improvements in measurement of dust on the FAAM aircraft in comparison to those from previous experiments such as DABEX, DODO and GERBILS. As shown in Rosenberg et al. (2012), the resulting agreement between the PCASP, CDP and CIP due to these calibrations is excellent.

Several other steps were necessary in the processing of the size distribution measurements. Firstly, several of the instruments do not have a defined minimum or maximum edge of the smallest and largest size bins respectively, so it is standard practice to exclude these size bins. The lowest size bins were removed from the PCASP, Grimm OPCs and CAS size distributions. The CAS suffered from a fault in the electronics affecting measurements at small diameters, and therefore measurements at nominal diameters smaller than $1.25 \mu \mathrm{m}$ (the smallest 10 size bins) are excluded. Finally the LTI requires that isokinetic conditions in the inlet are met, and in general this limits the operating altitude to beneath $1524 \mathrm{~m}$ (5000 feet), so measurements above this altitude are not used (Trembath et al., 2012).

The CIP was of particular importance during Fennec, enabling the sizes measured to be extended out as far as $930 \mu \mathrm{m}$. Accepted particles were sized using the mean of the maximum size in the $\mathrm{x}$ (along the axis of travel) and $\mathrm{y}$ (across the diode array) directions. The all-in approach described in Heymsfield and Parrish (1978) was used to describe the sample volume. In order to remove streaking and electronic noise from the CIP data, image events were rejected if any of the following criteria were met: (1) biggest particle aspect ratio greater than 2 and y width equal to 1 (streak), (2) Image event length/particle length $>4$ (noise), (3) aspect ratio $>5$ (noise), (4) particle area/bounding box area $<0.05$ (noise), (5) previous/next particle area equal to 1 and same array element (noise in diode element). CIP size distributions were also curtailed at a diameter of $300 \mu \mathrm{m}$ as these procedures did not always remove streaking and noise at sizes larger than this. Thus with the addition of the CIP we are able to measure further into the coarse mode for Saharan mineral dust than has been published for previous airborne experiments examining Saharan dust.

\subsubsection{Scattering and absorption measurements}

Scattering and absorption measurements were made by a TSI 3563 integrating nephelometer and a Radiance Research Particle Soot Absorption Photometer (PSAP), at wavelengths of 450, 550 and 700 and $567 \mathrm{~nm}$ respectively. Both instruments are situated inside the aircraft cabin, behind a modified Rosemount $102 \mathrm{E}$ inlet, designed originally to accommodate PRT temperature sensors.

PSAP filters were changed before every flight. Corrections are performed according to Turnbull (2010), who detail correction procedures necessary on the FAAM PSAP measurements as described by the original work by Bond et al. (1999) and further clarifications by Ogren (2010). We do not perform corrections described by Lack et al. (2008) relating to 
the effects of organic aerosol and light absorbing carbon, since dust was the dominant aerosol type present during Fennec. The standard corrections on the PSAP measurements limit the accuracy of the measured absorption coefficient to 20 to $30 \%$ (Johnson and Osborne, 2011; Lack et al., 2008).

Nephelometer measurements are corrected according to Anderson and Ogren (1998), using supermicron assumptions since particles sized up to $2 \mu \mathrm{m}$ were estimated to reach the nephelometer (see Sect. 2.2.3). The main source of error in the nephelometer measurements comes from the angular truncation correction, which accounts for scattering at angles smaller than $7^{\circ}$ and greater than $170^{\circ}$. Corrections based on Anderson and Ogren (1998) use a correction factor $\left(\mathrm{C}_{t s}\right)$ to total scattering which assumes a linear dependence on the Ångström exponent $(\AA)$. Quirantes et al. (2008) show that for supermicron particles this may result in errors when $\AA$ tends to zero. During Fennec, typical values of $\AA$ measured by the nephelometer between 450 and $700 \mathrm{~nm}$ were -0.4 to -0.3 . Heintzenberg et al. (2006) show that for mono-disperse size distributions of geometric mean diameter up to $2 \mu \mathrm{m}$, up to $35 \%$ of the scattered light is not measured due to angular truncation. This suggests the value of $\mathrm{C}_{t s}$ we use from Anderson and Ogren (1998) could result in $11 \%$ error (underestimate) in the measured scattering coefficient.

Combining the measurement uncertainties of the PSAP (assuming a maximum value of $30 \%$ ) and the nephelometer $(11 \%)$, as described above, results in typical upper error bounds of $11 \%$ in the extinction coefficient and $15 \%$ in SSA during Fennec. Lower error bounds are smaller at $1 \%$ and $3 \%$ for extinction coefficient and SSA respectively (since the nephelometer truncation scattering correction error results in increased scattering and therefore higher SSA). We note that the errors described here do not include under-sampling of coarse aerosols due to inlet effects, which we deal with separately in the following section.

Additionally, an identical nephelometer was set up in series with the first, with a BGI Very Sharp Cut Cyclone impactor between them, with a $50 \%$ penetration efficiency at $2.5 \mu \mathrm{m}$ aerodynamic diameter, equivalent to a geometric diameter of $1.5 \mu \mathrm{m}$. This allowed the scattering due to particles smaller than this diameter to be measured. During Fennec 2011 the second nephelometer typically measured scattering values $90 \%$ of those measured by the first nephelometer, indicating that most particles larger than $1.5 \mu \mathrm{m}$ did not reach the nephelometers. This is due to the Rosemount inlet and subsequent pipework removing most of the large particles before they reached the first nephelometer. Therefore only a small fraction of particles larger than $1.5 \mu \mathrm{m}$ remained to be removed by the impactor.

\subsubsection{Inlets}

Previously, difficulties have been encountered on the FAAM aircraft in estimating the fraction of supermicron particles measured by the nephelometer and the PSAP, due to their lo- cation inside the aircraft cabin, behind Rosemount inlets and connected to several metres of pipework (McConnell et al., 2010; McConnell et al., 2008; Johnson and Osborne, 2011). The measured optical properties are highly dependent on the extent to which the coarse mode is measured (McConnell et al., 2008). During Fennec, Grimm OPCs were setup behind two different Rosemount inlets, while a third was set up behind the fully characterised LTI inlet (Trembath et al., 2012; Wilson et al., 2004). This has enabled the proportion of the ambient size distribution passing through the Rosemount inlets on the FAAM aircraft to be examined for the first time, and here we use this information to assess the impact on the measured optical properties.

Transmission efficiencies of the sample runs (i.e. between the Rosemount inlet and the nephelometer and PSAP) have been estimated for the dominant transport loss processes using the specific sampling architecture for each instrument. Diffusive and gravimetric losses were calculated using empirical models of Hinds (1999) and Heyder and Gebhart (1977). Inertial losses were subdivided into three categories, losses associated with high velocity right angled sampling from the Rosemount inlet head, losses in contractions and losses in sample tube bends, which were estimated using the empirical models in Brixey et al. (2005), Muyshondt et al. (1996) and Piu et al. (1987) respectively. Electrophoretic and Thermophoretic losses were ignored as the sample temperature was considered stable in the first few centimetres of the sampling system and the use of stainless steel and conductive silicone tubing negates any issues associated with static charge. These models were parameterised for altitude specific sample line pressures, temperatures and a constant particle density of $2.65 \mathrm{~g} \mathrm{~cm}^{-3}$ for dust. Thus we take the measured size distribution with a Grimm OPC behind a Rosemount inlet and apply the sampling losses described above to calculate the size distribution as seen by the nephelometer and PSAP. We note that due to operational constraints, Grimm OPCs were set up behind Rosemount inlets supplying the cloud condensation nuclei $(\mathrm{CCN})$ instrument, and the aerosol mass spectrometer (AMS) inlet, rather than the Rosemount inlet supplying the nephelometer and the PSAP. This introduces an uncertainty in that we do not know whether the effects of the nephelometer/PSAP Rosemount inlet might differ. However, Trembath et al. (2012) shows that differences between the CCN and AMS Rosemount inlets are smaller than the effects of the enhancement.

Comparison of size distribution measurements from the LTI-Grimm with the size distributions representing that at the nephelometer and PSAP revealed that particle number concentration is increased by a factor of around 1.5 beneath diameters of $1.5 \mu \mathrm{m}$ at the nephelometer and PSAP. Enhancement then drops off with size, with no enhancements at diameters of around $2.5 \mu \mathrm{m}$, net losses between 2.5 and $5 \mu \mathrm{m}$, and no particles larger than $5 \mu \mathrm{m}$ being sampled. The exact enhancement varies with altitude. Figure 3 shows an example for altitudes of between 1 and $2 \mathrm{~km}$. The grey points show the 
size distribution calculated at the nephelometer (light grey diamonds) and the PSAP (dark grey diamonds) using measurements from the Grimm OPC behind the Rosemount inlet and the pipe loss calculations described above. Note that this is a combination of these two effects - for the effects solely of the Rosemount inlet we refer the reader to Trembath et al. (2012). The size distribution measured by the LTI Grimm OPC is shown in black triangles (for a descrption of the other instruments in this figure, see Sect. 2.4). It can be seen that at around $2.5 \mu \mathrm{m}$ the combined effect of the inlet and pipe losses change from an enhancement for smaller particles, to a net loss for larger particles. It is clear that most of the coarse mode particles are not able to contribute to scattering and absorption at the nephelometer and PSAP.

Grimm OPC measurements are available for only $18 \%$ of cases examined here, so we make the assumption that the data from these flights is representative of all flights. This may not be the case, and is an unquantified uncertainty; for example, the enhancement and losses may change with ambient size distribution. Enhancement and loss varies very slightly between the nephelometer and the PSAP due to the different sampling architecture for each instrument.

In this study, we take the enhancement factors, which vary with diameter and altitude, and account for both inlet losses and enhancements as well as pipe losses, and apply them to the size distributions measured by the wing probes, in order to simulate size distributions measured at the nephelometer and PSAP.

\subsection{Correction of size distribution for refractive index}

Optical sizing probes measure the scattering cross-section from a single particle and convert this to a particle size. Since the amount of scattering is dependent on the complex refractive index of the particle, $m$, (where $m=n+i k$ ), the size measurements here have been corrected for refractive indices typical of dust. Refractive index is assumed to be constant with particle size. (Initially sizes are calculated using refractive indices for PSL beads for the PCASP and water for the other optical probes are used). The method described by Rosenberg et al. (2012) is used here and software tools provided by these authors (CStoDConverter) have been used, assuming spherical particles. The resulting data includes uncertainties in particle size bins (both bin centres and bin widths) due to the non-monotonic nature of scattering as a function of size (i.e. due to the Mie scattering curve, it is possible for one value of scattering to correspond to more than one particle diameter). We present results assuming values of 1.53 for $n$, and 0.001 and 0.003 for $k$. Size distributions were also corrected using a range of other refractive indices $(n=1.42$, $1.58 ; k=0.006$ ) reflective of those in the literature (Wagner, 2012; Otto et al., 2009; McConnell et al., 2010; Johnson and Osborne, 2011; Petzold et al., 2009; Kim et al., 2011). However, results presented in Sect. 4.2 suggest that values of $\mathrm{m}$ between $1.53-0.001 i$ and $1.53-0.003 i$ were most appro-

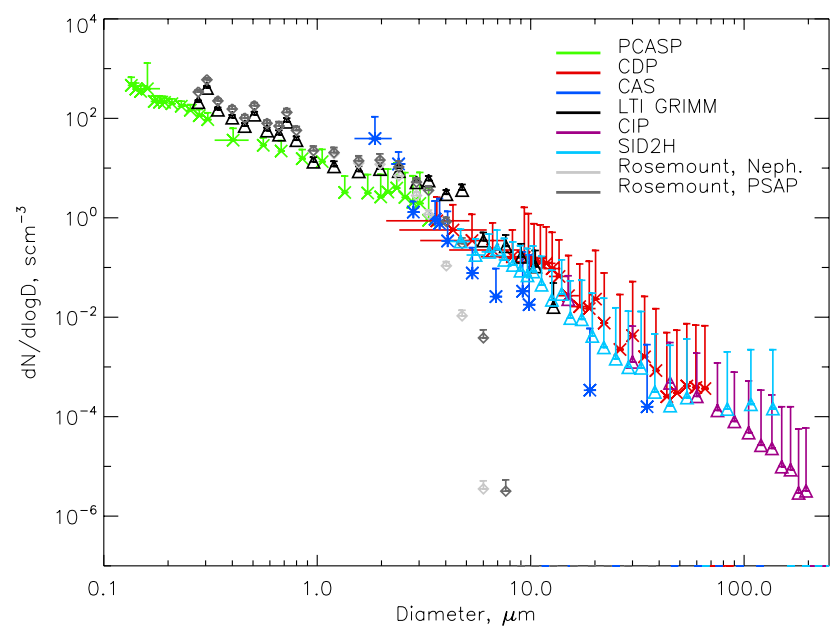

Fig. 3. Size distributions as measured by different instruments during Fennec 2011 for horizontal legs where all were operational, including refractive index corrections for $m=1.53-0.001$. Colors represent PCASP (green), LTI-GRIMM (black), CAS (dark blue), SID2H (light blue), CDP (red), CIP (purple). Size distributions reaching the nephelometer ("Neph." in caption) and PSAP are shown in light grey and dark grey diamonds respectively. This data includes effects of both Rosemount inlets and pipe losses. Vertical error bars indicate one standard deviation of the data. Upwards error bars only are shown for clarity. Horizontal error bars show uncertainty due to the non-monotonic relationship of scattering crosssection with particle size from refractive index corrections.

priate and therefore we present results using these values. We note that changing the real part of the refractive index did not have a significant effect on the results.

Table 3 shows the size ranges measured by each instrument. For the OPCs size ranges are shown as defined by the manufacturer ('nominal' size range), and once corrected for calibration (for PCASP, CDP and SID2H) and a refractive index appropriate for dust (all OPCs). Since the CIP is a shadow probe, CIP size bins do not need to be corrected for refractive index. For size ranges measured by the PCASP, the refractive index correction increases the measured size range by a factor of up to 1.3. This is slightly larger than found by Johnson and Osborne (2011) during GERBILS (values of 1.0 to 1.1) despite a similar refractive index, and may be due to the extra uncertainties in bin width incorporated here due to non-monotonic scattering. For the OPCs covering the larger sizes, the fractional increase in measured diameter increases with size due to the increased absorption at larger diameters. The maximum size measured increases by a factor of up to 4.5 for SID2H, which measures the largest size of all the OPCs. The maximum size measured by all the OPCs increases by a factor of between 1.3 to 4.5 , significantly increasing the extent to which the largest particles are represented: up to $267.4 \mu \mathrm{m}$ in the case of SID2H. It is noted that these corrections are somewhat larger than those used by Johnson and Osborne (2011) for SID2H during GERBILS, 
where the size bins were multiplied by a factor of 1.2. Possible differences could be due to the work by Johnson and Osborne (2011) using a scattering model assuming randomly orientated spheroids and particles smaller than $10 \mu \mathrm{m}$, and the CStoDConverter software used here allowing wider size bins due to non-monotonic scattering. For the LTI-GRIMM, size bins were corrected for refractive index before inlet enhancement corrections were performed, which has an impact as the enhancement corrections take into account particle mass and are therefore dependent on accurate bin sizes.

\subsection{Comparison of size distribution instrumentation}

Figure 3 compares the size distributions measured by the different instruments during 9 horizontal legs in Fennec when all were operational. Overall the agreement between the different instruments is good, and falls within the error bars, giving credence to the measurements. However, there are a few exceptions. Firstly the CAS did not perform well during Fennec, frequently not measuring any particles when all the other probes were detecting particles. For this reason the number concentrations at diameters greater than $5 \mu \mathrm{m}$ shown in Fig. 3 appear very low and are even zero in some cases. Therefore we do not use CAS data further in this study (but note that it has appeared to operate well in other experiments, e.g. Turnbull et al. (2012)). We note that the agreement between the CDP and the PCASP at $3-5 \mu \mathrm{m}$ is excellent, and in support of the measurement of realistic size distributions and an appropriate choice of refractive index. The agreement between the first two size bins of the CIP, and the CDP and SID2H is also very good at diameters of around 15 to $30 \mu \mathrm{m}$, adding credence to the measurements. We note that the CIP distribution is not dependent on choice of refractive index and that two different measurement techniques (optical and shadow-based) produce size distributions which are in agreement. The CDP and SID2H produce very similar measurements across their entire size ranges despite measuring over different scattering angles and at slightly different wavelengths (see Table 3). The CDP and the CIP data points lie very close together across the overlap range, while the same can be said of SID2H and the CIP data, except above $80 \mu \mathrm{m}$ where the SID2H diverges slightly from the CIP. Note that maximum particle sizes measured by the CDP and SID2H were limited by the sample volume sizes rather than their sensitive range. For example, the CDP could have measured particles up to $112.6 \mu \mathrm{m}$, and it rarely measured particles this large due to its smaller sample volume which did not often sample the larger, but less numerous particles. In contrast, the CIP has a sample volume over 300 times larger, and did measure particles at this size (see Fig. 3). As an example, during one horizontal flight leg during flight b612, when dust loadings were among the lighter observed during Fennec, the CDP measured zero particles in its largest size bin, while the CIP measured a mean of $2 \times 10^{-6}$ particles at the same size. The LTI-Grimm size distribution generally shows the same shape of size distribution to the other probes (excepting the CAS) although there are slight differences, with the LTI reporting slightly higher number concentrations than the CDP, SID2H and PCASP beneath around $5 \mu \mathrm{m}$, though many of these differences fall within the error bars.

Table 3 shows the percentage of in-situ horizontal legs during Fennec where each instrument was operational. These are not always $100 \%$ due to occasional instrument problems and aircraft altitude (in the case of LTI-GRIMM). Based on instrument data availability and the agreement and quality of the measured size distributions discussed above, measurements from the PCASP, CDP and CIP have been used henceforth in order to maintain consistency throughout the campaign. LTI-GRIMM data are also used from the cases available as they provide important information on the inlet losses.

\subsection{Parameterisation of size distributions}

The measured size distributions have been parameterised by a logfit curve representing four lognormal modes described according to,

$\frac{d N}{d \log D}=\frac{N_{\text {tot }}}{(2 \pi)^{1 / 2} \log \sigma_{\mathrm{g}}}\left(-\frac{\left(\log d_{\mathrm{p}}-\log d_{\mathrm{pg}}\right)^{2}}{2 \log ^{2} \sigma_{\mathrm{g}}}\right)$

where $d_{\mathrm{pg}}$ represents the median diameter, $\sigma_{g}$ is the geometric standard deviation and $\mathrm{N}_{t o t}$ is the total aerosol number concentration (Seinfeld and Pandis, 2006). The logarithm refers to base 10 . These were fitted automatically to the measurements using the MPFIT software (Markwardt, 2008) and incorporate uncertainties in the measured size distributions. Differences between measured and logfit size distributions were assessed by calculating the effective diameter $\left(d_{\text {eff }}\right.$,Equation 2$)$ for each,

$d_{\mathrm{eff}}=\frac{\int_{d_{\min }}^{d_{\max }} D^{3} \frac{d N}{d D} d D}{\int_{d_{\min }}^{d_{\max }} D^{2} \frac{d N}{d D} d D}$

Where $d_{\min }$ and $d_{\max }$ represent the minimum and maximum diameters covered by the size distribution, $\mathrm{D}$ is the particle diameter and $\mathrm{dN} / \mathrm{dD}$ is the number size distribution. In $82 \%$ of the cases, differences were smaller than $15 \%$, though the difference was larger for a small number of cases. For this reason we present results from both the direct size distribution measurements as well as from the logfit curves. We note that cases where the difference was largest are mostly cases where the logfit curves underestimate the measurements due to a couple of outliers in the measurements at large particle sizes. We supply modal parameters for the ease of provision of the size distribution data to the scientific community for further comparisons and validation of models. We also describe size distributions in terms of the coarse mode volume median diameter, $d_{\mathrm{vc}}$, which represents the fourth mode of the size distribution only, as defined in Weinzierl et al. (2009). 


\subsection{Derivation of refractive indices}

An iterative process is used to derive the imaginary part of the refractive index at $550 \mathrm{~nm}, k^{550}$, using the technique described by McConnell et al. (2010), and similar to that used by Petzold et al. (2009). Figure 4 depicts the iteration process used here to derive $k^{550}$. Ambient size distributions are input into a Mie scattering code, along with a refractive index at 550nm, where the real part $\left(n^{550}\right)$ is fixed at 1.53 and $k^{550}$ was varied. The refractive index is assumed to be constant with particle size, which seems a reasonable assumption based on detailed chemical analyses of dust (Kandler et al., 2009), at least in terms of hematite being the main absorbing compound in dust. The calculated scattering and absoprtion coefficients, $\sigma_{\mathrm{s}}^{550}$ and $\sigma_{\mathrm{a}}^{550}$, were then used to calculate $\omega_{0}^{550}$. The calculated value of $\omega_{0}^{550}$ was compared to that measured by the nephelometer and PSAP. This sequence was then repeated with values of $k^{550}$ from 0.001 to 0.008 . The value of $k^{550}$ which gave the closest agreement was chosen as the best estimate. This process was carried out separately for each horizontal leg during Fennec.

For consistency, the size distribution used as input to the Mie code should represent the size distribution reaching the nephelometer and PSAP. In one approach, the measured size distribution can be cut-off at $3 \mu \mathrm{m}$, assuming particles larger than this do not pass through the Rosemount inlets, as in McConnell et al. (2010). Alternatively, the measurements of the losses and enhancements in the Rosemount inlets and pipework (see Sect. 2.2.3) can be applied to the measured size distributions, to more accurately represent the size distribution reaching the nephelometer and PSAP, and this adjusted size distribution can be used as input to the Mie scattering code. Here we employ the latter method in an attempt to more accurately represent the size distribution reaching the nephelometer and PSAP. Both these methods still only provide information on the refractive index for the accumulation mode, as this is constrained by the maximum particles sizes which the nephelometer and PSAP can measure via the aircraft inlets.

\subsection{Identification of dust sources and dust age}

Broad geographic dust source regions for the dust sampled during Fennec 2011 have been identified by following SEVIRI RGB satellite images backwards in time and by locating the regions where dust was first evident in the images. Since this technique is subjective and sometimes ambiguous if the dust is not very obvious in the images, if dust loadings are light, low altitude or in a moist atmosphere, for example (Brindley et al., 2012), HYSPLIT back trajectories (Draxler and Hess, 1998) have also been run over 5 days. In all cases the back trajectories agreed with the Seviri interpretation, except for the case of b604. The meteorology affecting the dust in this case differs from the rest of the flights in that the dust was uplifted by a mesoscale convective system (MCS)

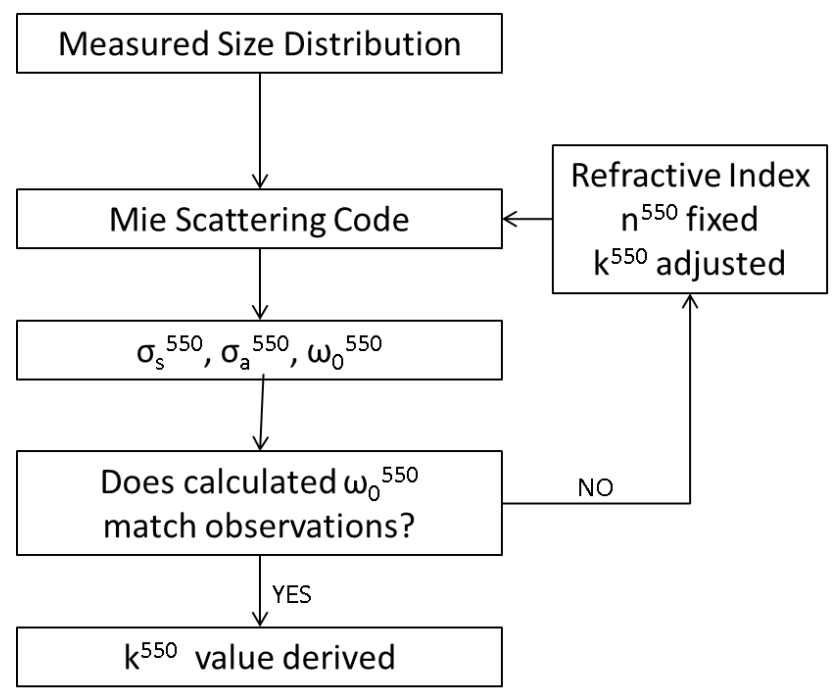

Fig. 4. Flow chart showing iteration process for deriving $k^{550}$ for the accumulation mode. $n^{550}$ is assumed to be 1.53. Input size distribution is adjusted for losses and enhancements due to Rosemount inlets and pipe losses.

with a well-defined dust front over central Mali (Sodemann et al., 2013). In contrast, the other events during Fennec were caused by more synoptic-scale flows. The low resolution of the meteorological information input to Hysplit (one degree) therefore make it less likely to be able to correctly resolve the convection and associated dust uplift (Heinold et al., 2009; Marsham et al., 2011). Dust sampled during Fennec 2011 has been categorised into event types based on the age of the dust sampled and the dominant meteorology. These categories are described in Sect. 5 Where source regions were not evident, horizontal legs were not categorised. A more detailed analysis of dust sources and meteorology during Fennec 2011 can be found in McQuaid et al. (2013)

\subsection{Radiative transfer calculations}

Semi-idealised radiative transfer calculations are employed in order to demonstrate the impact of the size distributions on shortwave (solar) atmospheric heating rates. The setup is designed to be as simple as possible to illustrate the effect of SSA and size distribution on radiative fluxes and atmospheric heating rates; further studies will employ more detailed radiative transfer models. We use the Edwards and Slingo radiative transfer model (Edwards and Slingo, 1996; Randles et al., 2012) with a plane-parallel atmosphere and model irradiance from 0.2 to $10 \mu \mathrm{m}$ with 220 spectral bands. A standard tropical atmosphere was used for vertical profiles of atmospheric gases (Anderson et al., 1986). Dust is situated between 0 to $5 \mathrm{~km}$ altitude with a total aerosol optical depth at $550 \mathrm{~nm}$ of 1.0. Surface albedo is spectrally constant across solar wavelengths at 0.33 to represent a desert surface (e.g. Christopher et al. 2011). Values of 0.2 and 0.45 are also 

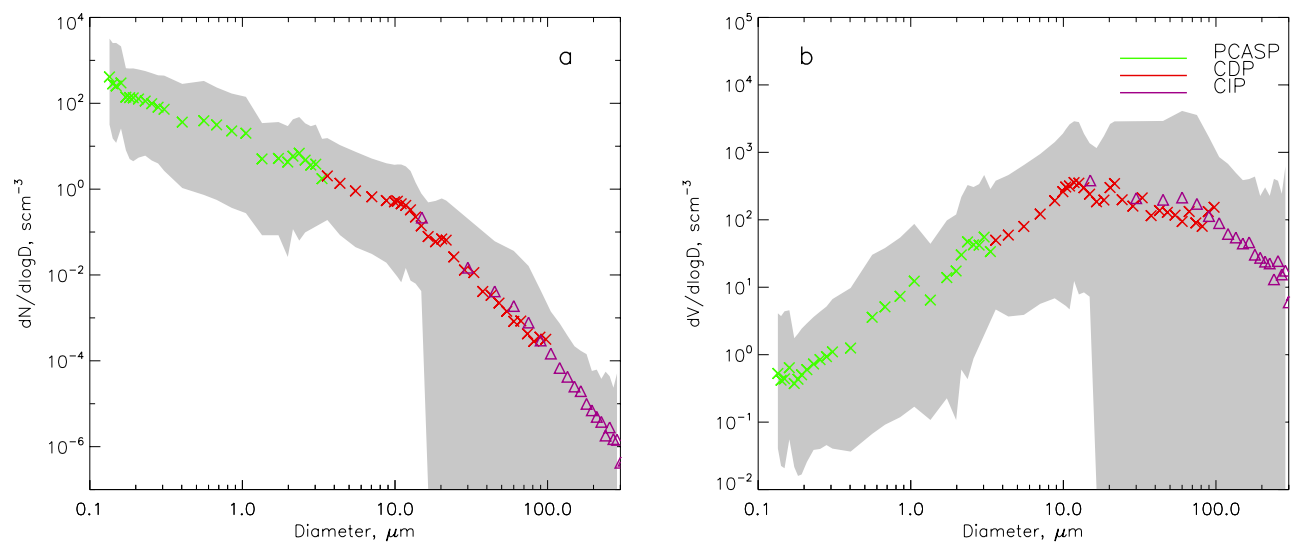

Fig. 5. Mean size distributions measured during Fennec 2011 horizontal legs, for number distribution (a) and volume distribution (b). Data from the PCASP (green crosses), CDP (red crosses) and CIP (purple triangles) have been used. Grey shading represents minimum and maximum values measured during Fennec horizontal legs.

tested to derive maximum uncertainties due to geographical surface albedo variations. Solar zenith angle is set to zero. SSA values are specified to represent the range of values presented in Sect. 4.1, representing the different size distributions measured during Fennec 2011. Instantaneous heating rates for an overhead sun are calculated.

\section{Size distribution measurements}

Figure 5 shows the mean and range of size distributions measured during horizontal legs within dust layers during Fennec, using data from the PCASP, CDP and CIP, in terms of number distribution (Fig. 5a) and volume distribution (Fig. 5b). The grey shading indicates considerable variability in the number concentration of the size distributions, of over two orders of magnitude for much of the size range measured, and increasing to more than three orders of magnitude variability for particles larger than $30 \mu \mathrm{m}$. This reflects the wide range of dust loadings encountered during the campaign.

The size distribution from each horizontal leg has been fitted with logfit curves. The mean (black line) and envelope (grey shading) are shown in Fig. 6, and the parameters describing each of the four modes are given in Table 4. SAMUM1, SAMUM2, GERBILS and DODO are also shown. For each of the SAMUM campaigns, two lines represent the measured range. The grey shading, indicating the spread of size distributions measured during Fennec 2011, clearly overlaps with that measured during the other campaigns, particularly at sizes smaller than around $3 \mu \mathrm{m}$. This suggests that the different source areas and transport distances affecting the different campaigns has little effect on the accumulation mode size distribution, and is in agreement with other studies which have found little change in size distribution with transport (Reid et al., 2008; Chen et al., 2011), or in lidar-measured optical properties (Liu et al., 2008). How-
Table 4. Lognormal mode parameters and dvc of the Fennec minimum, mean and maximum size distribution as shown in Fig. 6. Diameters are given in microns, number concentrations in $\mathrm{scm}^{-3}$.

\begin{tabular}{llllll}
\hline & & Mode 1 & Mode 2 & Mode 3 & Mode 4 \\
\hline Min & $d_{\mathrm{pg}}$ & 0.06 & 0.71 & 2.50 & 5.0 \\
& $\sigma_{\mathrm{g}}$ & 2.00 & 1.35 & 1.45 & 1.50 \\
& $N_{\text {tot }}$ & 30.00 & 0.15 & 0.03 & 0.03 \\
& $d_{\mathrm{vc}}$ & & & & 8.12 \\
Mean & $d_{\mathrm{pg}}$ & 0.05 & 0.71 & 2.04 & 5.28 \\
& $\sigma_{\mathrm{g}}$ & 2.50 & 1.33 & 1.45 & 2.00 \\
& $N_{\text {tot }}$ & 508.27 & 8.84 & 1.89 & 0.54 \\
& $d_{\mathrm{vc}}$ & & & & 22.31 \\
$\operatorname{Max}$ & $d_{\mathrm{pg}}$ & 0.05 & 0.65 & 2.25 & 4.50 \\
& $\sigma_{\mathrm{g}}$ & 2.50 & 1.40 & 1.35 & 2.20 \\
& $N_{\text {tot }}$ & 2525.00 & 100.00 & 15.00 & 5.00 \\
& $d_{\mathrm{vc}}$ & & & & 29.05 \\
\hline
\end{tabular}

ever, at sizes larger than $3 \mu \mathrm{m}$ measurements from different campaigns show much more variability, though there is still a degree of overlap between the different campaigns. The size distributions from Fennec show the greatest amount of variability, perhaps due to the larger number of samples, the larger spatial scales, the varying time since emission and the range of dust loadings sampled. The Fennec size distributions also show the greatest abundance of coarse mode, with the mean size distribution having $d_{\mathrm{pg}}$ of the fourth mode at $5.28 \mu \mathrm{m}$ and the coarse mode volume median diameter $\left(d_{\mathrm{vc}}\right)$ being $22.32 \mu \mathrm{m}(8.12$ and $29.05 \mu \mathrm{m}$ for the minimum and maximum respectively, see Table 4). Effective diameters of the full size distribution cover 2.4 to $19.4 \mu \mathrm{m}$. Interestingly, Fennec measured more coarse mode than was encountered during SAMUM-1, which was previously considered an outlier in terms of the amount of coarse mode measured (Johnson and Osborne, 2011; Formenti et al., 2011a). 

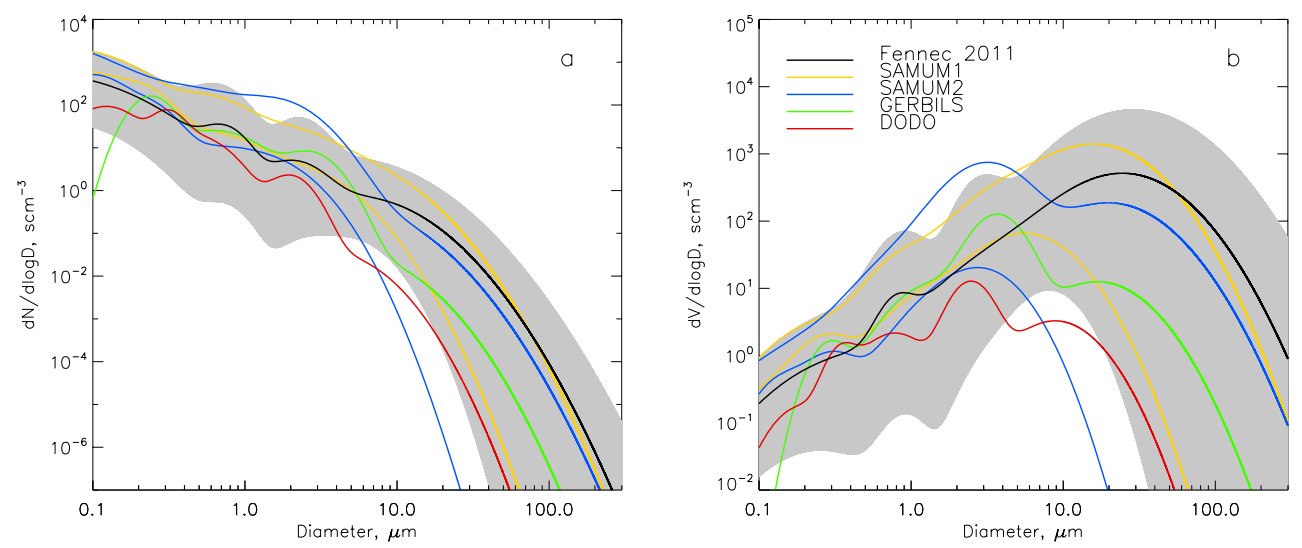

Fig. 6. Mean Fennec 2011 size distribution compared to those from other recent aircraft campaigns, for (a) number distribution and (b) volume distribution. Fennec size distribution is shown in black, with grey shading representing the minimum and maximum throughout the campaign. Other campaigns shown are SAMUM-1 (yellow lines), SAMUM-2 (blue lines), GERBILS (green line) and DODO flight b238 (red line). Where two lines are present in the same color they represent an envelope of size distributions (SAMUM-1 and SAMUM-2). GERBILS and DODO size distributions have been scaled by number concentrations typical of Fennec, as published values are normalised. The DODO size distribution is not corrected for refractive index.
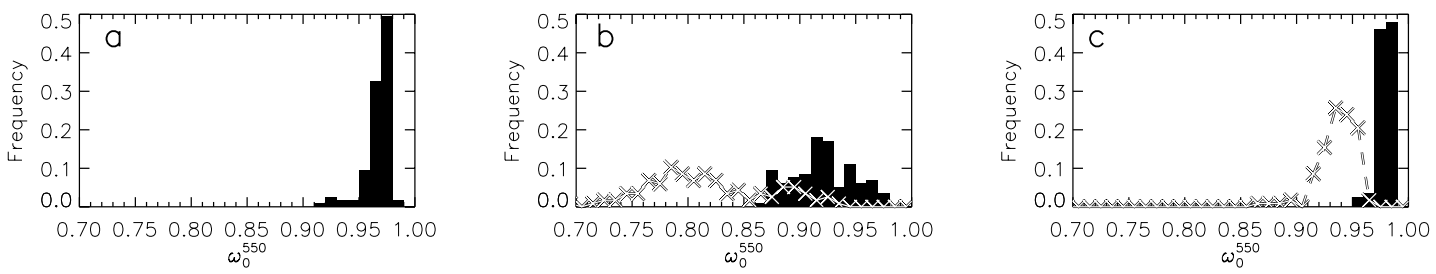

Fig. 7. Histograms of single scattering albedo values at $550 \mathrm{~nm}$ from horizontal legs during Fennec: (a) from observations as measured by the nephelometer and PSAP behind Rosemount inlets; (b) Calculated using the full size distributions as shown in Fig. 5; (c) Calculated using size distributions adjusted for inlet and pipe losses and enhancements, i.e. with reduced coarse mode. Solid bars in (b) and (c) assume $m=1.53-0.001 i$, dashed lines and crosses assume $m=1.53-0.003 i$.

SAMUM-1 effective diameters covered 2.45 to $12.19 \mu \mathrm{m}$ (3rd and 97th percentiles) and $d_{\mathrm{vc}} 15.5 \pm 10.9 \mu \mathrm{m}$ (Weinzierl et al., 2011). Both Fennec and SAMUM-1 have in common that the measurement locations were very close to fresh dust sources, whereas the other campaigns measured dust transported over greater distances. Fennec was also located further towards the centre of the Sahara desert than the previous campaigns, and sampled some very large dust loadings with aerosol optical depths greater than 2.0 (larger than measured in SAMUM-1), and therefore the abundance of larger particles could be due to Fennec 2011 being the first instance of an aircraft sampling such heavy dust loadings.

\section{Optical properties}

\subsection{Single scattering albedo}

Figure 7 shows histograms of $\omega_{0}^{550}$ values for the dust encountered during horizontal legs in Fennec. The panels show values from measurements (Fig. 7a) and from Mie scattering calculations (Fig. $7 \mathrm{~b}$ and c) using the measured size distri- butions. We note that the measurements (Fig. 7a) are made behind Rosemount inlets and therefore do not measure particles larger than around 2 to $3 \mu \mathrm{m}$, and also measure an enhanced number concentration of accumulation mode particles, as described in Sect. 2.2.3. For the calculated $\omega_{0}^{550}$ values, for Fig. 7b, size distribution measurements covering all particle sizes up to $300 \mu \mathrm{m}$ are used (as shown in Fig. 5), while in Fig. 7c the size distributions have been adjusted to represent that reaching the nephelometer and PSAP, in order to replicate the measurements of the accumulation mode, based on the inlet and pipework losses and enhancements described in Sect. 2.2.3. The latter two methods use a Mie scattering code, assume spherical particles and a refractive index $m$ (constant with particle size) of 1.53-0.001i (solid bars) and $1.53-0.003 i$ (dashed line) at $550 \mathrm{~nm}$. The assumptions of spherical particles and a constant refractive index with particle size both introduce uncertainties which are not explored further here.

The SSAs from direct measurements range from 0.91 to 0.99 (Fig. 7a). The majority of the measurements fall within the range 0.95 to 0.98 , and values smaller than this were 
measured during flight b600, which measured the heaviest dust loadings. The uncertainty bounds on the measured SSA are estimated at $3 \%$ (lower bound) to $15 \%$ (upper bound). The lower bound results in an uncertainty of 0.03 , while the higher bound pushes the distribution of SSA values towards unity. The results are similar to those measured previously for dust (McConnell et al., 2008; Haywood et al., 2003; Osborne et al., 2008; Johnson and Osborne, 2011; Petzold et al., 2009; Petzold et al., 2011), using inlets which restrict the measurement of coarse particles. The measurements are consistent with the conclusions drawn from many of these publications that dust has low absorption properties.

Figure $7 \mathrm{~b}$ shows the SSA values calculated from Mie code when considering the full size distribution, including the coarse particles which are not sampled by Rosemount inlets. The SSA values now range from 0.86 to 0.97 for $k^{550}=0.001$, and from 0.70 to 0.93 for $k^{550}=0.003$, considerably lower than the values shown in Fig. 7a. The mean is $0.92(0.82)$, with 10th and 90th percentiles at 0.88 and 0.96 (0.76 and 0.90) respectively for $k^{550}=0.001\left(k^{550}=0.003\right)$. Changing $k^{550}$ from 0.001 to 0.003 significantly reduces the SSA via two methods: firstly the instrument size bins are slightly larger which results in more larger particles, which have greater absorption capabilities. Secondly the larger $k^{550}$ results in more absorption from the Mie scattering calculations. These results are now comparable with studies from SAMUM where the full size distribution of dust has also been used to calculate SSA, such as Otto et al. (2009) who found SSA values of around 0.80 at $550 \mathrm{~nm}$, and values from Müller et al. (2010) of around 0.82 at $550 \mathrm{~nm}$. The uncertainties in the measured SSA in Fig. 7a (3 to $15 \%$ lower and upper error bounds) are not enough to reconcile the differences between Fig. 7a and Fig. 7b.

Figure 7c shows the SSA values calculated using the size distributions adjusted to represent that reaching the nephelometer and PSAP. The values now cover 0.95 to 0.99 ; similar to the distribution shown in Fig. 7a. The better level of agreement between Fig. 7a and Fig. 7c supports the argument that scattering and absorption measurements behind Rosemount inlets prevents measurement of the full size distribution, and results in an overestimate of the SSA in cases where coarse particles are present, as is the case for mineral dust, particularly when close to dust sources. The dashed line shows the SSA values calculated with the same adjusted size distribution, but with $k^{550}=0.003$. This results in lower SSA values than the observed values shown in Fig. 7a (from measurements). Therefore it appears more likely that a representative imaginary refractive index for the dust sampled is $k^{550}=0.001$.

Since there is a clear effect of the large particles on SSA, we show the relationship directly in Fig. 8a. There is an obvious decrease in SSA as the effective diameter increases, due to the absorbing effect of the larger particles. Therefore the degree of overestimation of the SSA by measurements behind the Rosemount inlets is dependent on the amount of coarse mode present, as illustrated by Fig. 8b. If insignificant numbers of particles are present at diameters greater than $3 \mu \mathrm{m}$, then loss through the inlets and in pipework will be minimal. During the horizontal legs within dust during Fennec, the maximum overestimate of SSA by the nephelometer and PSAP was 0.11 , and the nephelometer/PSAP combination ceased to overestimate the SSA once effective diameter dropped below $2 \mu \mathrm{m}$. Figure $8 \mathrm{~b}$ shows that this overestimation will be amplified as effective diameter of the ambient dust size distribution increases. It is therefore critical for aircraft to supplement dust aerosol measurements behind inlets with wing probe measurements, which do not suffer from inlet effects in order to evaluate the extent to which measurements behind aircraft inlets are biased. We also tested the relationship of $d_{\mathrm{vc}}$ to SSA, and found no similar decline in SSA with increasing $d_{\mathrm{vc}}$ (not shown). This illustrates the fact that it is the proportion of coarse to fine particles which is important for the SSA, not just the total amount of coarse mode.

The extent to which previous aircraft measurements of dust overestimate SSA will depend on the ambient size distributions, and whether significant numbers of particles larger than $3 \mu \mathrm{m}$ are present. For example, Osborne et al. (2011) validated the in-situ measurements of dust during GERBILS with radiative transfer calculations and airborne radiation measurements. The coarse mode during GERBILS was measured with the same SID2H instrument as shown in Fig. 3, which appears to show similar amounts of coarse mode as the other instruments during Fennec. Instrumental differences therefore seem unlikely, pointing towards a real difference in the amount of coarse mode present and resultant optical properties present during GERBILS in comparison to Fennec 2011 and SAMUM. Johnson and Osborne (2011) show vertical profiles of elevated dust, perhaps indicating that the dust measured during GERBILS had undergone longer transport distances than that during Fennec, where the dust layers were densest closest to the ground. This may explain why GERBILS encountered fewer coarse particles.

\subsection{Refractive indices}

As described in Sect. 2.6 it is possible to derive refractive indices for the accumulation mode. Figure 9 shows the frequency distribution of the derived imaginary part of the refractive index for horizontal legs during Fennec, assuming a real part of 1.53 . The size distribution is corrected using an imaginary part $\left(k^{550}\right)$ of 0.001 (solid bars) and 0.003 (dashed line). For $k^{550}=0.001$, the values range from $0.001 i$ to $0.004 i$, with 10th and 90th percentiles at 0.001 and 0.002 respectively, and both a mean and median of 0.002 . When size distributions are corrected using $k^{550}=0.003$ (dashed line) the mean (and median) refractive index is 0.001 , which is clearly inconsistent. Using $k^{550}=0.003$ results in larger particles and more absorption, which then requires a smaller value of $k^{550}$ in order to achieve closure with the measured 

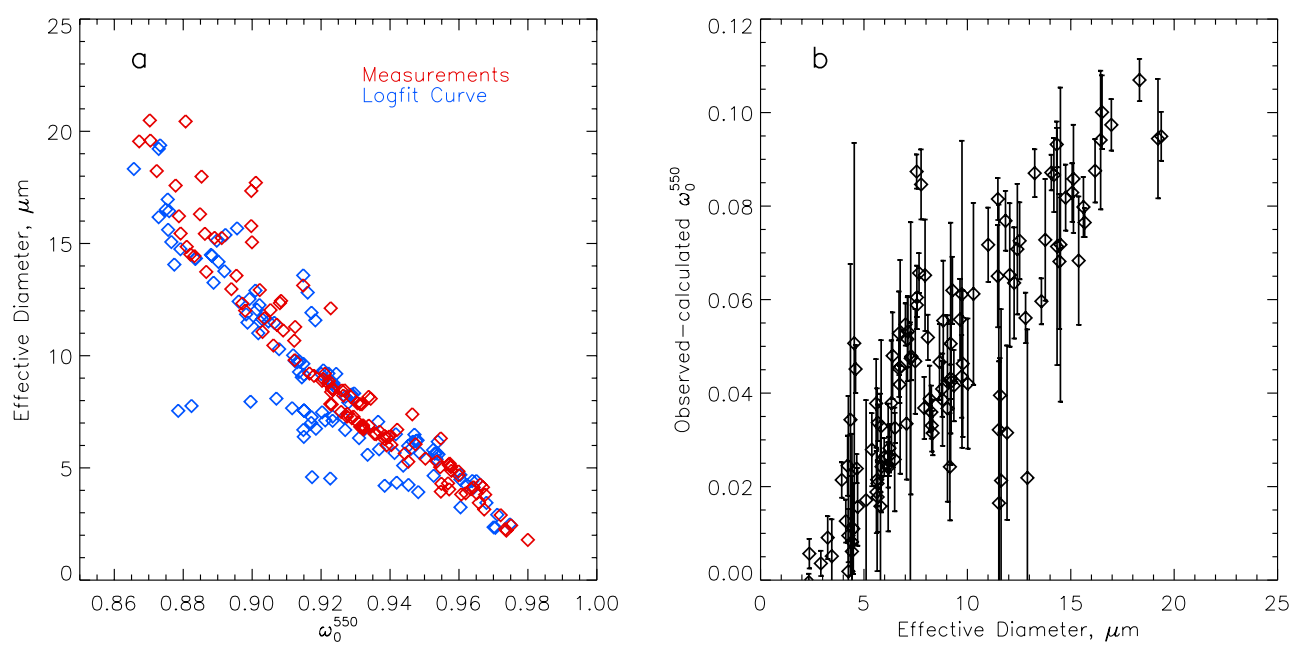

Fig. 8. (a) Comparison of $d_{\mathrm{eff}}$ to $\omega_{0}^{550}$ using measurements of the full size distribution. Red points indicate size distributions using the measured data, blue points indicate data calculated from logfits to the size distribution. (b) Overestimate of measured $\omega_{0}^{550}$ (accumulation mode only) compared to calculated $\omega_{0}^{550}$ (full size range) as a function of effective diameter. Each data point represents one horizontal leg. Error bars show uncertainty in measurement SSA due to atmospheric variability across each horizontal leg.

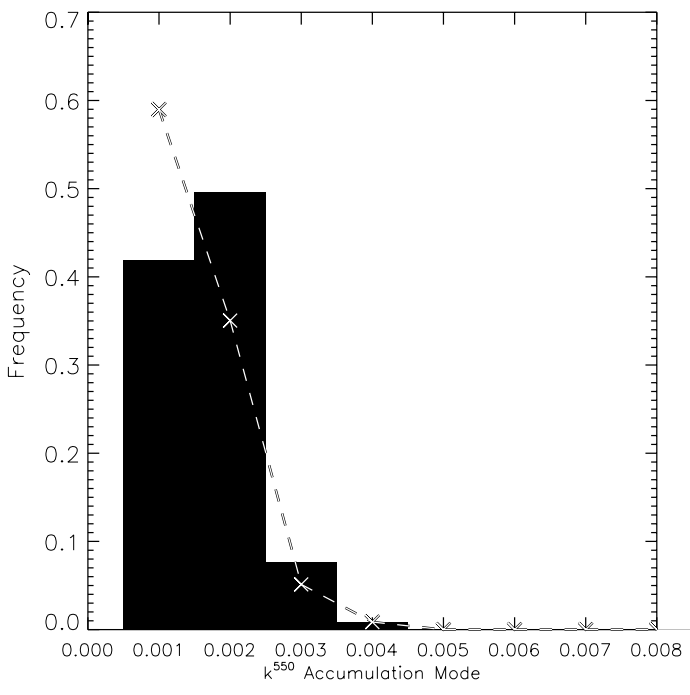

Fig. 9. Histogram showing derived k550 values for the accumulation mode for horizontal legs during Fennec. Solid bars show derivations using size distributions corrected using $k^{550}=0.001 i$, dashed line and crosses show derivations using size distributions corrected using $k^{550}=0.003 i$.

SSA. This inconsistency, in addition to the inconsistency shown in Fig. 7c for $k^{550}=0.003$ (dashed line) suggests that 0.003 is not an appropriate refractive index for the accumulation mode for Fennec 2011, whereas 0.001 is more consistent. We note that the uncertainties in $k^{550}$ due to SSA measurement uncertainties are of the order 0.002 . The range of values shown in Fig. 9 are very similar to those estimated in other recent studies varying between 0.0001 to 0.0046 (McConnell et al., 2010; Petzold et al., 2009; Petzold et al., 2011;
Formenti et al., 2011a), supporting the view that the imaginary part of the refractive index is relatively small at wavelengths of $550 \mathrm{~nm}$.

\section{Factors influencing size distribution and optical properties}

Since the measurements indicate that during Fennec there was a large proportion of coarse particles present and that this has a significant impact on lowering the SSA, it is important to examine factors which may affect the concentration of larger particles, such as the altitude of measurement, dust event type, dust age and dust source region.

Since it is feasible that the largest particles may not be transported up to higher altitudes, in Fig. 10 we show the relationship between SSA, $d_{\mathrm{eff}}, d_{\mathrm{vc}}$ and altitude of measurement. The results are heavily biased towards low altitudes, where most of the horizontal legs took place (see Fig. 2). There is a large variability of $d_{\text {eff }}$ at low altitudes with values ranging from 2 to $19 \mu \mathrm{m}$ beneath pressure heights of $1.2 \mathrm{~km}$ (around $1 \mathrm{~km}$ above ground level) for the logfit case, and with values confined between 4 and $11 \mu \mathrm{m}$ at altitudes above $1.5 \mathrm{~km}$, similar to values in Weinzierl et al. (2009). $d_{\mathrm{vc}}$ shows a similar behaviour, despite the fact that $d_{\mathrm{vc}}$ represents only the fourth mode of the size distribution while $d_{\text {eff }}$ represents the whole size range.

Figure 10 suggests that the largest particles were mostly encountered at altitudes beneath $1.2 \mathrm{~km}$. However, this conclusion should be viewed with slight caution for several reasons. Firstly the sample number is larger at lower altitudes, so statistically there was more chance of sampling a range of dust concentrations closer to the surface. Secondly, by 

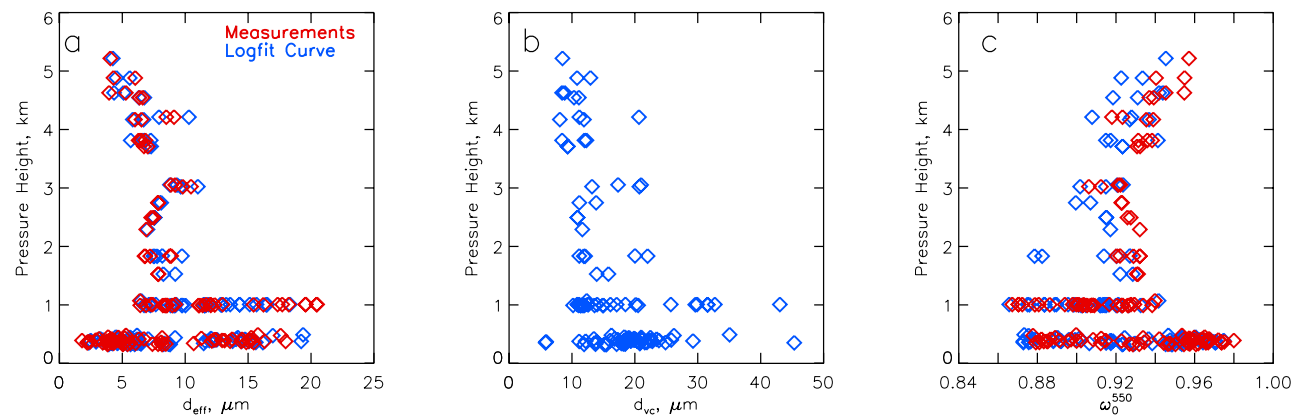

Fig. 10. Scatter plots showing (a) $d_{\mathrm{eff}}$, (b) $d_{\mathrm{vc}}$ and (c) $\omega_{0}^{550}$ against measurement altitude in terms of pressure height. All data points are calculated from the full size distribution. Red points show calculations using the size distributions directly from the measurements, blue points show calculations using the logfit curves.

necessity the altitude of measurement was determined by dust loadings. For example, when dust loadings were light, the aircraft flew close to the ground to sample the highest concentrations of dust, and may not have sampled much smaller particles higher up. When dust loadings were very heavy, the aircraft could not fly beneath $800 \mathrm{~m}$ due to the low visibility, and may have missed sampling even larger particles at lower altitudes. Therefore the representation of the results in Fig. 10 must be viewed with some caution as they are dependent on the measurement altitude of the aircraft during each flight. However, with these caveats in mind, the data shown in Fig. 10 does show that the largest particles encountered during Fennec were only sampled at low altitudes. Although Fig. 10a and Fig. 10b show that fewer large particles were encountered at higher altitudes, the particles there are still of reasonable size, with $d_{\mathrm{vc}}$ values of up to $20 \mu \mathrm{m}$ up to $4.5 \mathrm{~km}$ high, and up to $10 \mu \mathrm{m}$ at $5 \mathrm{~km}$ altitudes, consistent with Weinzierl et al. (2009) who found particles larger than $40 \mu \mathrm{m}$ at $5 \mathrm{~km}$ altitudes. $1.2 \mathrm{~km}$ is both the maximum convective boundary layer depth during the morning breakdown of the nocturnal low level jet and of cold pool outflows, the two dominant mechanisms of dust production in the summertime Sahara (Marsham et al., 2013; Marsham et al., 2011).

Since there is an inverse relationship between SSA and $d_{\text {eff }}$ (Fig. 8) the relationship between SSA and altitude (Fig. 10c) is the inverse of that of $d_{\mathrm{eff}}$ and altitude (Fig. 10a). Lowest values of SSA tend to be found at lower altitudes, though the same caution described above in terms of $d_{\mathrm{eff}}$ and $d_{\mathrm{vc}}$ must also be applied to SSA. The fact that SSA appears to be lowest closer to the surface is interesting in terms of implications for atmospheric heating rates - in the shortwave (solar) it would imply that dust would have the largest heating effect in the lower Saharan boundary layer. In terms of the longwave (terrestrial) effect, it would weaken the atmospheric radiative cooling effect of the dust if the largest particles are closest to the surface, but strengthen the surface warming (Liao and Seinfeld, 1998).

Figure 1 shows the likely geographical source regions for the dust sampled during different flights and dust event types during Fennec, from the methodology described in Sect. 2.7. horizontal legs and sources are color-coded to separate different source locations, dust event types and transport distances. The categories include two cases of very fresh dust being sampled - firstly three flights over northern Mali (b600, b601 and b602) caused by strong northeasterly winds (black), and secondly flight b610 over northeastern Mauritania (blue). Flight b604 sampled an aged cold pool MCS which was initiated over Mali and transported westwards to Mauritania. Dust sampled on 21 June (b605, b606, yellow) was uplifted by convection over the Atlas Mountains in Morocco which instigated a cold pool and transported dust southwards towards Mauritania (Kocha et al., 2013a, b). Finally several flights throughout the final part of the campaign (b609, b611, b612, b613) sampled aged dust, which was most likely uplifted by northeasterly winds over central Algeria (red).

For each of the dust events and source regions shown in Fig. 1, dust properties have been calculated and are shown in Fig. 11, to include effective diameter, number concentration, mass loading, SSA, extinction coefficient and $k^{550}$. These properties are shown against the estimated dust age from uplift. Several of the categories in Fig. 11 have many horizontal legs included while others only include a few. The error bars for the dust properties represent the range of values seen over all cases used in each category. The error bars for dust age represent generous uncertainties on the dust age estimated using Seviri RGB images, due to the slightly subjective method. Dust age impacts size distributions by three mechanisms: with time, freshly uplifted dust is diluted by plumes mixing out horizontally, the dusty BL entrains cleaner air from above and larger particles preferentially fall out to the ground.

Figure 11a shows that the categories with the larger $d_{\mathrm{eff}}$ values tend to be the less aged categories - notably the 'fresh uplift' cases from both Mali and Mauritania contain cases with $d_{\text {eff }}$ greater than $12 \mu \mathrm{m}$. The trend in the mean $d_{\text {eff }}$ (indicated by data points) with dust age shows a decrease, although there is a large spread in values (error bars). The relationship between dust age and $d_{\mathrm{vc}}$ is somewhat similar with 

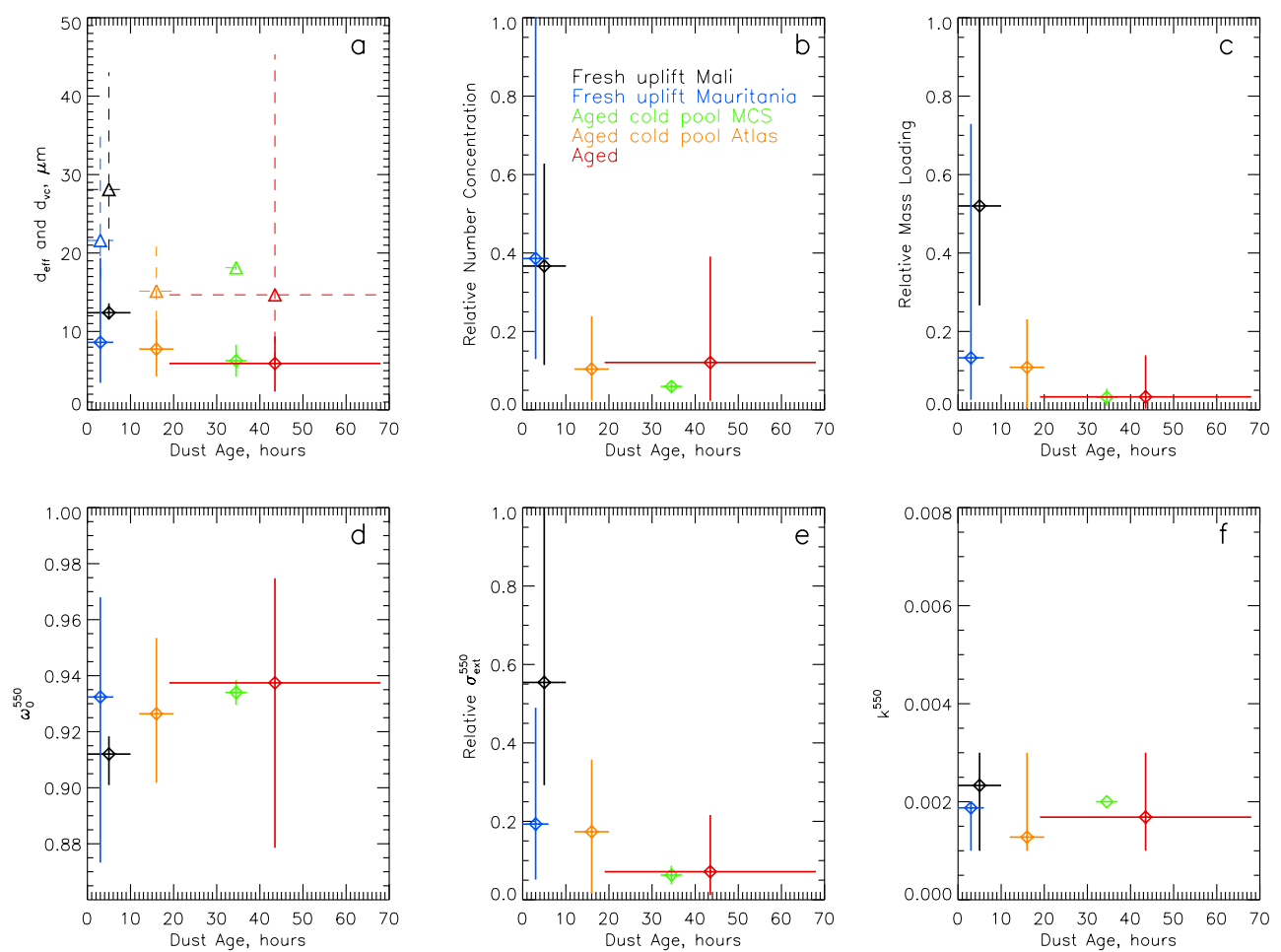

Fig. 11. Relationship between dust age since uplift and (a) deff (solid lines and diamonds) and dvc (dashed lines and triangles); (b) relative total number concentration; (c) relative mass loading; (d) $\omega_{0}^{550}$; (e) relative $\sigma_{\text {ext }}^{550}$ and (f) accumulation mode $k^{550}$. Horizontal and vertical lines represent the range of values observed in each category, data points represent the mean. Events are categorised as described in the text covering fresh dust uplifted in Mali (black), fresh dust uplifted in Mauritania (blue), aged dust uplifted by an MCS over Mali (green), aged dust uplifted by a cold pool originating over the Atlas Mountains (yellow), and aged dust uplifted over central Algeria (red). All parameters apart from $\mathrm{k} 550$ represent the full size distribution.

the "fresh uplift" cases having mean values of 28 and $22 \mu \mathrm{m}$, and the other cases having lower values of 15 to $18 \mu \mathrm{m}$. Other than this, the relationship is somewhat unclear with outliers in the "aged" category having very large $d_{\mathrm{vc}}$ values in some cases. This is perhaps due to the relationship between dust size distribution and age being affected by other factors such as soil type and uplift wind speed. Interestingly the average wind speed at measurement altitude was $13.3 \mathrm{~ms}^{-1}$ for the "fresh uplift" case in Mali (at around $800 \mathrm{~m}$ a.g.1.), but only $11.6 \mathrm{~ms}^{-1}$ for the "fresh uplift" case in Mauritania (at around $100 \mathrm{~m}$ a.g.l.). This may also contribute to the larger particles present in the fresh Mali case compared to the fresh Mauritania case. Thus there is some suggestion in Fig. 11a that the largest particles are deposited faster than the smaller ones during transport, with a potential exponential relationship. Previous studies suggest, contrastingly, that uplifted size distributions are remarkably constant with windspeed (Kok, 2011b), and alternatively some wind tunnel experiments suggest that larger wind speeds uplift smaller particles (Alfaro, 2008). It has also been found that size distribution shape does not change substantially with transport (Reid et al., 2008; Formenti et al., 2011a; Liu et al., 2008), which is not consistent with sedimentation theory, nor with the results presented here, although Maring et al. (2003) found that particles larger than $7.3 \mu \mathrm{m}$ were preferentially removed during trans-Atlantic transport.

A different picture is seen in terms of dust total number concentration (Fig. 11b). Here number concentration decreases with dust age in general, presumably because as the dust plumes spread out dust concentrations are diluted and particles are lost due to dry deposition. The data falls into broadly two classes - firstly for ages less than $10 \mathrm{~h}$ uplift into an approximately $1 \mathrm{~km}$ deep CBL is ongoing and number concentrations are high. For ages greater than $10 \mathrm{~h}$ the uplift into a shallow layer has ended, and this shallow layer is now in the process of being mixed or has already been mixed into the $5 \mathrm{~km}$ deep Saharan boundary layer, with concentrations decreasing accordingly. The Mauritania uplift case displays particularly high values due to high number concentrations in the submicron particle size range (not shown). The relationship with mass loading (Fig. 11c) largely echoes the number concentration relationship, though due to the greater contribution of the larger particles to total mass loading, the shape of the size distribution now becomes important. The fresh uplift Mali case now stands out with the largest mass loading due to these flights measuring the greatest proportions of 
Table 5. Atmospheric dust instantaneous shortwave heating rates resulting from different SSA values and size distributions from radiative transfer calculations, using a broadband surface albedo of 0.33 .

\begin{tabular}{lllll}
\hline & \multicolumn{2}{c}{ Full size distribution } & \multicolumn{2}{l}{ Size Distribution behind aircraft inlets } \\
\hline$k^{550}$ & $0.001 i$ & $0.003 i$ & $0.001 i$ & $0.003 i$ \\
$\omega_{0}^{550}$ range & 0.86 to 0.97 & 0.70 to 0.93 & 0.95 to 0.99 & 0.86 to 0.96 \\
Shortwave heating & 0.04 to 0.18 & 0.09 to 0.34 & 0.02 to 0.06 & 0.05 to 0.18 \\
rate range, $\mathrm{K} \mathrm{h}^{-1}$ & & & & \\
\hline
\end{tabular}

coarse particles, whereas the fresh uplift Mauritania case has a lower mass loading due to the greater number of smaller particles. The overall trend is one of decreasing mass loading with increasing dust age.

It is interesting to note that despite the fact that we present two "fresh uplift" cases, their characteristics are quite different. In the case observed over Mali, wind speeds were larger and a greater proportion of coarse particles were present resulting in larger $d_{\mathrm{eff}}, d_{\mathrm{vc}}$ and mass loadings. In the case observed over Mauritania wind speeds were lower, as were $d_{\mathrm{eff}}, d_{\mathrm{vc}}$ and mass loadings, but total number concentrations were much higher. Correspondingly, aerosol optical depths (AODs) at $550 \mathrm{~nm}$ measured by the nephelometer and PSAP were 0.9 to 2.7 for the Mali case and 0.4 to 1.5 for the Mauritania case. Therefore the Mali case was characterised by high AODs, larger particles and larger mass loadings, whereas the Mauritania case was characterised by lower AODs, smaller particles, and higher number concentrations.

In terms of the optical properties as a function of age, there appears to be an increase in mean SSA with dust age if the "fresh Mauritania" case is excepted, mirroring the trend of decreasing $d_{\text {eff }}$ with dust age. The relationship between SSA and dust age is not a strong one, with outliers and the "fresh Mauritania" case suggesting that there are other factors contributing to SSA. Composition is likely to be a strong factor and change with dust source location (Formenti et al., 2011b) which is neglected here, since the derived refractive indices here only represent the accumulation mode.

$\sigma_{\text {ext }}^{550}$ (Fig. 11e) is determined by both the number concentration and size distribution, and shows a similar relationship with age to Fig. $11 \mathrm{~b}$ and Fig. 11c. $k^{550}$ for the accumulation mode (Fig. 11f) shows very little relationship to dust age and different source regions do not appear to have different $k^{550}$ values, in contrast to previous work (e.g. McConnell et al., 2010), though again we note that these $k^{550}$ values only represent the accumulation mode.

\section{Impact of optical properties on atmospheric heating rates}

Table 5 shows how the different size distributions and SSA values from measurements of the full size distribution and from measurements only representing particles passing through the Rosemount inlets on the aircraft affect instanta- neous shortwave atmospheric heating rates for a solar zenith angle of zero. Heating rates for the range of SSA values shown in Fig. 8b and $\mathrm{c}$ are presented. The heating rates are instantaneous for an overhead sun, and will change during the day.

As expected, lower values of SSA result in greater atmospheric heating. For $k^{550}$ of 0.001 (considered most likely), the effect of the SSA from the full size distribution compared to that measured behind the aircraft inlets changes the range of heating rates from 0.02 to $0.06 \mathrm{~K} \mathrm{~h}^{-1}$ (behind the inlets) to 0.04 to $0.18 \mathrm{~K} \mathrm{~h}^{-1}$ (for the full size distribution), an increase of 2 to 3 times. For the alternative value of $k^{550}=0.003$ considered, the resultant heating rates are even larger, increasing from 0.05 to $0.18 \mathrm{~K} \mathrm{~h}^{-1}$ to 0.09 to $0.34 \mathrm{~K} \mathrm{~h}^{-1}$ when the full size distribution is considered, a factor of 1.8 to 1.9 . The sensitivity due to changing the surface albedo from 0.33 to values of 0.2 and 0.45 results in a change in absolute heating rate of up to $50 \%$ in some cases. However, the magnitude of the amplification in heating rates due to using a lower single scattering albedo lies in the range 1.5 to 2.9 , similar to the values stated above.

These larger heating rates which account for the presence of large particles may therefore have a potentially large impact on boundary layer development and atmospheric circulation over the Sahara, and calculations which only take into account measurements behind size-selective aircraft inlets could be substantial underestimates.

\section{Conclusions}

The new dataset from the Fennec 2011 aircraft campaign is novel for three main reasons. Firstly the measurements were taken in a remote part of the Sahara desert, northern Mauritania and northern Mali, a region from where no aircraft measurements of dust have previously been possible, therefore representing an advance of in-situ aircraft measurements further towards the difficult-to-reach centre of the Sahara. Secondly, the new size distribution instrumentation operated on the FAAM aircraft has allowed measurements of dust coarse mode particles to be extended to larger sizes $(300 \mu \mathrm{m}$ diameter) than previous experiments have achieved, enabling mineral dust size distributions to be better constrained. Thirdly, the dust events that were sampled were varied in terms of dust loading, dust age and dust source location, enabling the 
size distribution instrumentation to deliver new results concerning dust characteristics under different dust loadings in the remote location.

Measurements of the size distribution during Fennec 2011 revealed a significant coarse mode of dust which was always present, with $d_{\mathrm{vc}}$ values from 5.8 to $45.3 \mu \mathrm{m}$ and effective diameters from 2.3 to $19.4 \mu \mathrm{m}$, with the mean size distribution having values of $d_{\mathrm{eff}}$ and $d_{\mathrm{vc}}$ of $9.0 \mu \mathrm{m}$ and $22.3 \mu \mathrm{m}$ respectively. The size distribution volume concentration varied by at least two orders of magnitude, and by six orders of magnitude at diameters of $50 \mu \mathrm{m}$. In comparison to other aircraft measurements over the Sahara, the range measured during Fennec overlapped with that from SAMUM and GERBILS, though the Fennec mean was larger (for example, during SAMUM-1 the mean $d_{\mathrm{vc}}$ was $15.5 \mu \mathrm{m}$ ). Both Fennec 2011 and SAMUM-1 stand out as having a larger number of coarse particles present. These campaigns have in common that they measured dust closer to source regions, with shorter transport times and distances than other campaigns. Thus it seems likely that the largest particles are present close to the source, but are not transported much further afield.

The abundance of coarse mode dust particles measured close to dust sources and over remote desert regions during Fennec and SAMUM-1 suggests that large particles are more prevalent over desert regions than previously thought. This may have a significant impact on satellite retrievals over the desert, such as the SEVIRI-RGB thermal infrared dust product (Brindley et al., 2012), which has been used to infer dust source regions (Schepanski et al., 2007; Ashpole and Washington, 2012) and can be used as preferential dust source regions in models (Schepanski et al., 2009; Heinold et al., 2011) and for dust model evaluation (Johnson et al., 2011). The abundance of large particles may have implications for other satellite retrievals over desert surfaces which make assumptions on dust size and/or optical properties. The presence of a greater number concentration of coarse particles may also be a limitation in sunphotometer dust size distribution retrievals over desert regions, such as by AERONET, which do not extend beyond $30 \mu \mathrm{m}$ diameter (e.g. Müller et al. (2010)).

An important question is whether, and for how long, these larger particles remain in the atmosphere during transport, and whether the large heating rates due to the large particles persist as dust is transported across the Atlantic Ocean. During Fennec 2011 the FAAM aircraft intercepted dust transport over the Canary Islands during most flights departing and returning to Fuerteventura, and analysis of this data will provide insight into this.

Single scattering albedos at $550 \mathrm{~nm}$ have been calculated for the dust sampled during Fennec using the full range of sizes measured, revealing low values covering the range 0.86 to 0.97 for $k^{550}=0.001$, and from 0.70 to 0.93 for $k^{550}=0.003$. The SSA has been shown to be sensitive to effective diameter: size distributions with the largest effective diameters produced the lowest SSA values.
Two Grimm OPCs behind a LTI and a Rosemount inlet have been used to calculate the particle enhancements and losses affecting nephelometer and PSAP measurements on the FAAM aircraft behind Rosemount inlets. SSA calculations taking into account measured size distributions, inlet enhancements and pipe losses reflected the measurements of SSA (0.91 to 0.99) more accurately than that using the full size distribution. These calculations reveal that measuring the SSA behind inlets which do not sample the full coarse mode results in an overestimate of SSA, by up to 0.11 during Fennec. This overestimate increases as effective diameter of the ambient aerosol increases. When effective diameters were less than $2 \mu \mathrm{m}$ there was no overestimate. This highlights the importance of using wing-mounted probes to measure the full size distribution of dust to enable calculation of their optical properties, and suggests that older measurements of dust SSA values on aircraft may have been overestimates (Haywood et al., 2003; Osborne et al., 2008; McConnell et al., 2008), though this depends on the effective diameter of the ambient aerosol.

Despite the limitations of Rosemount inlets for dust measurements, useful measurements can be made behind them, but it must be emphasised that they only represent the accumulation mode and that significant deviations can occur when coarse mode is included. For example, scattering and absorption measurements behind Rosemount inlets have been successfully used here to derive imaginary parts of the refractive index at $550 \mathrm{~nm}$, and show that values of $0.001 i$ and $0.002 i$ are most common.

An investigation of particle size, represented by $d_{\mathrm{eff}}$ and $d_{\mathrm{vc}}$, and measurement altitude, showed that the largest particles with $d_{\text {eff }}$ greater than $12 \mu \mathrm{m}$ ( or $d_{\mathrm{vc}}$ greater than $25 \mu \mathrm{m}$ ) were mainly encountered within $1 \mathrm{~km}$ of the ground, and a large fraction of these were within $100 \mathrm{~m}$ of the ground. Correspondingly, the lowest SSA values calculated were also closest to the ground. However, this finding should be viewed with caution as the sampling altitude varied with dust loading and visibility, and sample sizes were greater at lower altitudes. Analysis of data from profiles made during Fennec will be presented in a further study to investigate this in a more statistically representative way.

In this study we represented dust particles as spheres, while in reality dust aerosol is non-spherical, which adds some uncertainty to the results presented here. This is present firstly in the derivation of the size distribution, in the conversion of a scattering cross section to a particle diameter, which will differ for non-spherical particles, and secondly in the calculation of the optical properties using the measured size distributions. In the first case, the agreement between the PCASP, CDP and CIP suggests that the size distributions are being interpreted correctly, especially since the CIP distribution is generated using a shadowing technique. In the second case, Otto et al. (2009) find that $\omega_{0}$ changed by under $1 \%$ due to the effect of non-sphericity. Additionally, Johnson and Osborne (2011) found variations of under $2 \%$ due to 
irregular spheroids compared to spheres. These changes are much smaller than the variation of over $20 \%$ shown in Fig. 7.

The in-situ measurements were categorised by their general dust source location and dust event type, in order to try to determine factors which may have caused the prevalence of larger particles. Sources included locations in north Mali, western Mali, northeast Mauritania, central Algeria and the region of Algeria close to the Moroccan border. Dust event types included two fresh uplift cases caused by strong winds - one over Mali and one over Mauritania, aged dust associated with a MCS originating in Mali, aged dust transported by a cold pool near the Atlas Mountains, and more general regional aged dust. Dust age since uplift was then calculated for each of these categories. A decrease in $d_{\mathrm{eff}}$ and $d_{\mathrm{vc}}$ with dust age was found. A similar inverse weak relationship between SSA and dust age was found. Strong relationships were seen in number concentration and mass loading, with a decrease in both with dust age. The two fresh uplift cases showed different characteristics, despite having similar dust age, with the Mali case having larger particles but lower number concentrations, and the opposite for the Mauritanian case. Wind speeds and size were larger in the Mali case, although other factors such as surface soil type and surface moisture may also play a role.

Heating rates for the range of different SSA values were calculated, and showed that using the full size distribution (with a lower range of SSA values) increased atmospheric shortwave heating rates due to dust by up to three times. Thus there are potentially important implications of estimating SSA using measurements behind aircraft inlets, as these larger heating rates will effect atmospheric circulation and dynamics such as Saharan boundary layer development. In addition, longwave (terrestrial) heating rates, and overall radiative effect of dust at the top and bottom of the atmosphere will be impacted.

The growing body of evidence for the presence of large coarse mode particles over the Sahara and associated low SSA values indicates that significant absorption over desert regions is likely. It is important that dust and climate models use appropriate optical properties for dust in order to adequately represent these effects.

Acknowledgements. Core project funding for Fennec was from the UK Natural Environmental Research Council (NERC) under grant NE/G017166/. Airborne data was obtained using the BAe-146-301 Atmospheric Research Aircraft operated by Directflight Ltd and managed by FAAM, which is a joint entity of the NERC and the UK Met Office. The authors acknowledge the dedicated work of FAAM, Directflight and Avalon during the aircraft campaign. We acknowledge the data provision for the SID2H instrument from Richard Cotton, Met Office, and the data processing for the CAPS instrument by Ian Crawford, University of Manchester. We acknowledge the contributions of all the First Mission Scientists involved in the aircraft campaign, particularly Luis Garcia-Carerras, Doug Parker, and
Martin Todd. H. S. was funded through the EUFAR Transnational Access project LADUNEX.

Edited by: M. Gysel

\section{References}

Ackerley, D., Joshi, M. M., Highwood, E., Ryder, C., Harrison, M. A. J., Walters, D., Milton, S., and Strachan, J.: A comparison of two dust uplift schemes within the HadGAM2 climate model, Q. J. Roy. Meteor. Soc., 260515, doi:10.1155/2012/260515, 2012.

Alfaro, S. C.: Influence of soil texture on the binding energies of fine mineral dust particles potentially released by wind erosion, Geomorphology, 93, 157-167, doi:10.1016/j.geomorph.2007.02.012, 2008.

Anderson, G. P., Clough, S. A., Kneizys, F. X., Chetwynd, J. H., and Shettle, E. P.: AFGL atmospheric constituent profiles (0120 km), Technical Report AFGL-TR-86-0110, AFGL (OPI), Hanscom. AFB, MA. 01736, 1986.

Anderson, T. L. and Ogren, J. A.: Determining aerosol radiative properties using the TSI 3563 integrating nephelometer, Aerosol Sci. Technol., 29, 57-69, 1998.

Ansmann, A., Petzold, A., Kandler, K., Tegen, I., Wendisch, M., Müller, D., Weinzierl, B., Müller, T., and Heintzenberg, J.: Saharan Mineral Dust Experiments SAMUM-1 and SAMUM-2: what have we learned?, Tellus B, 63, 403-429, doi:10.1111/j.16000889.2011.00555.x, 2011.

Ashpole, I. and Washington, R.: An automated dust detection using SEVIRI: A multiyear climatology of summertime dustiness in the central and western Sahara, J. Geophys. Res.-Atmos., 117, D08202, doi:10.1029/2011jd016845, 2012.

Banks, J. R. and Brindley, H. E.: Evaluation of MSG-SEVIRI mineral dust retrieval products over Africa and the Middle East, Remote Sensing of Environment, 128, 58-73, doi:10.1016/j.rse.2012.07.017, 2013.

Baumgardner, D., Jonsson, H., Dawson, W., O'Connor, D., and Newton, R.: The cloud, aerosol and precipitation spectrometer: a new instrument for cloud investigations, Atmos. Res., 59, 251264, 2001.

Bond, T. C., Anderson, T. L., and Campbell, D.: Calibration and intercomparison of filter-based measurements of visible light absorption by aerosols, Aerosol Sci. Technol., 30, 582-600, doi:10.1080/027868299304435, 1999.

Brindley, H., Knippertz, P., Ryder, C., and Ashpole, I.: A critical evaluation of the ability of the Spinning Enhanced Visible and Infrared Imager (SEVIRI) thermal infrared red-green-blue rendering to identify dust events: Theoretical analysis, J. Geophys. Res.-Atmos., 117, D07201, doi:10.1029/2011jd017326, 2012.

Brixey, L. A., Evans, D. E., and Vincent, J. H.: Aspiration efficiency of a thin-walled probe at right angles to the wind, J. Aerosol Sci., 36, 1144-1156, doi:10.1016/j.jaerosci.2004.12.007, 2005.

Chen, G., Ziemba, L. D., Chu, D. A., Thornhill, K. L., Schuster, G. L., Winstead, E. L., Diskin, G. S., Ferrare, R. A., Burton, S. P., Ismail, S., Kooi, S. A., Omar, A. H., Slusher, D. L., Kleb, M. M., Reid, J. S., Twohy, C. H., Zhang, H., and Anderson, B. E.: Observations of Saharan dust microphysical and optical properties from the Eastern Atlantic during NAMMA airborne field campaign, Atmos. Chem. Phys., 11, 723-740, doi:10.5194/acp11-723-2011, 2011. 
Christopher, S. A., Gupta, P., Johnson, B., Ansell, C., Brindley, H., and Haywood, J.: Multi-sensor satellite remote sensing of dust aerosols over North Africa during GERBILS, Q. J. Roy. Meteor. Soc., 137, 1168-1178, doi:10.1002/Qj.863, 2011.

Cotton, R., Osborne, S., Ulanowski, Z., Hirst, E., Kaye, P. H., and Greenaway, R. S.: The Ability of the Small Ice Detector (SID-2) to Characterize Cloud Particle and Aerosol Morphologies Obtained during Flights of the FAAM BAe146 Research Aircraft, J. Atmos. Ocean. Tech., 27, 290-303, doi:10.1175/2009jtecha1282.1, 2010.

Cuesta, J., Marsham, J. H., Parker, D. J., and Flamant, C.: Dynamical mechanisms controlling the vertical redistribution of dust and the thermodynamic structure of the West Saharan atmospheric boundary layer during summer, Atmos. Sci. Lett., 10, 34-42, doi:10.1002/Asl.207, 2009.

Draxler, R. R. and Hess, G. D.: An overview of the HYSPLIT_4 modeling system of trajectories, dispersion, and deposition, Austral. Meteorol. Mag., 47, 295-308, 1998.

Dunion, J. P. and Velden, C. S.: The impact of the Saharan air layer on Atlantic tropical cyclone activity, B. Am. Meteorol. Soc., 85, 353-365, doi:10.1175/Bams-85-3-353, 2004.

Edwards, J. M., and Slingo, A.: Studies with a flexible new radiation code .1. Choosing a configuration for a large-scale model, Q. J. Roy. Meteor. Soc., 122, 689-719, 1996.

Evan, A. T., Heidinger, A. K., Bennartz, R., Bennington, V., Mahowald, N. M., Corrada-Bravo, H., Velden, C. S., Myhre, G., and Kossin, J. P.: Ocean temperature forcing by aerosols across the Atlantic tropical cyclone development region, Geochem. Geophys. Geosyst., 9, Q05V04, doi:10.1029/2007gc001774, 2008.

Formenti, P., Rajot, J. L., Desboeufs, K., Said, F., Grand, N., Chevaillier, S., and Schmechtig, C.: Airborne observations of mineral dust over western Africa in the summer Monsoon season: spatial and vertical variability of physico-chemical and optical properties, Atmos. Chem. Phys., 11, 6387-6410, doi:10.5194/acp-11-6387-2011, 2011a.

Formenti, P., Schütz, L., Balkanski, Y., Desboeufs, K., Ebert, M., Kandler, K., Petzold, A., Scheuvens, D., Weinbruch, S., and Zhang, D.: Recent progress in understanding physical and chemical properties of African and Asian mineral dust, Atmos. Chem. Phys., 11, 8231-8256, doi:10.5194/acp-11-8231-2011, $2011 \mathrm{~b}$.

Forster, P., Ramaswamy, V., Artaxo, P., Berntsen, T., Betts, R., Fahey, D. W., Haywood, J., Lean, J., Lowe, D. C., Myhre, G., Nganga, J., Prinn, R., Raga, G., Schulz, M., and Van Dorland, R.: Changes in Atmospheric Constituents and in Radiative Forcing, in: Climate Change 2007: The Physical Science Basis, in: Contribution of Working Group I to the Fourth Assessment Report of the Intergovernmental Panel on Climate Change, edited by: Solomon, S., Qin, D., Manning, M., Chen, Z., Marquis, M., Averyt, K. B., Tignor, M., and Miller, H. L., Cambridge University Press, Cambridge, UK, 2007.

Haywood, J., Francis, P., Osborne, S., Glew, M., Loeb, N., Highwood, E., Tanre, D., Myhre, G., Formenti, P., and Hirst, E.: Radiative properties and direct radiative effect of Saharan dust measured by the C-130 aircraft during SHADE: 1 . Solar spectrum, J. Geophys. Res.-Atmos., 108, 8577, doi:10.1029/2002jd002687, 2003.

Haywood, J. M., Allan, R. P., Culverwell, I., Slingo, T., Milton, S., Edwards, J., and Clerbaux, N.: Can desert dust explain the outgoing longwave radiation anomaly over the Sa- hara during July 2003?, J. Geophys. Res.-Atmos., 110, D05105, doi:10.1029/2004jd005232, 2005.

Haywood, J. M., Pelon, J., Formenti, P., Bharmal, N., Brooks, M., Capes, G., Chazette, P., Chou, C., Christopher, S., Coe, H., Cuesta, J., Derimian, Y., Desboeufs, K., Greed, G., Harrison, M., Heese, B., Highwood, E. J., Johnson, B., Mallet, M., Marticorena, B., Marsham, J., Milton, S., Myhre, G., Osborne, S. R., Parker, D. J., Rajot, J. L., Schulz, M., Slingo, A., Tanre, D., and Tulet, P.: Overview of the Dust and Biomass-burning Experiment and African Monsoon Multidisciplinary Analysis Special Observing Period-0, J. Geophys. Res.-Atmos., 113, D00C17, doi:10.1029/2008jd010077, 2008.

Haywood, J. M., Johnson, B. T., Osborne, S. R., Baran, A. J., Brooks, M., Milton, S. F., Mulcahy, J., Walters, D., Allan, R. P., Klaver, A., Formenti, P., Brindley, H. E., Christopher, S., and Gupta, P.: Motivation, rationale and key results from the GERBILS Saharan dust measurement campaign, Q. J. Roy. Meteor. Soc., 137, 1106-1116, doi:10.1002/QJ.797, 2011.

Heim, M., Mullins, B. J., Umhauer, H., and Kasper, G.: Performance evaluation of three optical particle counters with an efficient "multimodal" calibration method, J. Aerosol Sci., 39, 1019-1031, doi:10.1016/j.jaerosci.2008.07.006, 2008.

Heinold, B., Tegen, I., Esselborn, M., Kandler, K., Knippertz, P., Müller, D., Schladitz, A., Tesche, M., Weinzierl, B., Ansmann, A., Althausen, D., Laurent, B., Massling, A., Müller, T., Petzold, A., Schepanski, K., and Wiedensohler, A.: Regional Saharan dust modelling during the SAMUM 2006 campaign, Tellus B, 61, 307-324, doi:10.1111/j.1600-0889.2008.00387.x, 2009.

Heinold, B., Tegen, I., Schepanski, K., Tesche, M., Esselborn, M., Freudenthaler, V., Gross, S., Kandler, K., Knippertz, P., Müller, D., Schladitz, A., Toledano, C., Weinzierl, B., Ansmann, A., Althausen, D., Müller, T., Petzold, A., and Wiedensohler, A.: Regional modelling of Saharan dust and biomass-burning smoke Part I: Model description and evaluation, Tellus B, 63, 781-799, doi:10.1111/j.1600-0889.2011.00570.x, 2011.

Heintzenberg, J., Wiedensohler, A., Tuch, T. M., Covert, D. S., Sheridan, P., Ogren, J. A., Gras, J., Nessler, R., Kleefeld, C., Kalivitis, N., Aaltonen, V., Wilhelm, R. T., and Havlicek, M.: Intercomparisons and aerosol calibrations of 12 commercial integrating nephelometers of three manufacturers, J. Atmos. Ocean. Tech., 23, 902-914, doi:10.1175/Jtech1892.1, 2006.

Heintzenberg, J.: The SAMUM-1 experiment over Southern Morocco: overview and introduction, Tellus B, 61, 2-11, doi:10.1111/j.1600-0889.2008.00403.x, 2009.

Heyder, J. and Gebhart, J.: Gravitational deposition of particles from laminar aerosol flow through inclined circular tubes, J. Aerosol Sci., 9, 289-295, 1977.

Heymsfield, A. J. and Parrish, J. L.: Computation Technique for Increasing Effective Sampling Volume of Pms1 2-Dimensional Particle-Size Spectrometer, J. Appl. Meteorol., 17, 1566-1572, 1978.

Highwood, E. J., Haywood, J. M., Silverstone, M. D., Newman, S. M., and Taylor, J. P.: Radiative properties and direct effect of Saharan dust measured by the C-130 aircraft during Saharan Dust Experiment (SHADE): 2. Terrestrial spectrum, J. Geophys. Res.-Atmos., 108, 8578, doi:10.1029/2002jd002552, 2003.

Hinds, W. C.: Aerosol technology: properties, behavior, and measurement of airborne particles, Wiley, New York, USA, 75-105, 1999. 
Hobby, M., Gascoyne, M., Marsham, J. H., Bart, M., Allen, C., Engelstaedter, S., Dieh, A., Gandega, R., Lane, L. B., McQuaid, J., Ouchene, B., Ouladichir, A., Parker, D. J., Rosenberg, P., Salah Ferroudj, M., Saci, A., Seddik, F., Todd, M., Walker, D., and Washington, R.: The Fennec Automatic Weather Station (AWS) Network: monitoring the Saharan Climate System, J. Atmos. Ocean. Technol., doi:10.1175/JTECH-D-12-00037.1, in press, 2012.

Huneeus, N., Schulz, M., Balkanski, Y., Griesfeller, J., Prospero, J., Kinne, S., Bauer, S., Boucher, O., Chin, M., Dentener, F., Diehl, T., Easter, R., Fillmore, D., Ghan, S., Ginoux, P., Grini, A., Horowitz, L., Koch, D., Krol, M. C., Landing, W., Liu, X., Mahowald, N., Miller, R., Morcrette, J. J., Myhre, G., Penner, J., Perlwitz, J., Stier, P., Takemura, T., and Zender, C. S.: Global dust model intercomparison in AeroCom phase I, Atmos. Chem. Phys., 11, 7781-7816, doi:10.5194/acp-11-7781-2011, 2011.

Ito, A., Kok, J., Feng, Y., and Penner, J.: Does a theoretical estimation of the dust size distribution at emission suggest more bioavailable iron deposition?, Geophys. Res. Lett., 39, L05807, doi:10.1029/2011GL050455, 2012.

Jickells, T. D., An, Z. S., Andersen, K. K., Baker, A. R., Bergametti, G., Brooks, N., Cao, J. J., Boyd, P. W., Duce, R. A., Hunter, K. A., Kawahata, H., Kubilay, N., laRoche, J., Liss, P. S., Mahowald, N., Prospero, J. M., Ridgwell, A. J., Tegen, I., and Torres, R.: Global iron connections between desert dust, ocean biogeochemistry, and climate, Science, 308, 67-71, 2005.

Johnson, B. T., Brooks, M. E., Walters, D., Woodward, S., Christopher, S., and Schepanski, K.: Assessment of the Met Office dust forecast model using observations from the GERBILS campaign, Q. J. Roy. Meteor. Soc., 137, 1131-1148, doi:10.1002/Qj.736, 2011.

Johnson, B. T. and Osborne, S. R.: Physical and optical properties of mineral dust aerosol measured by aircraft during the GERBILS campaign, Q. J. Roy. Meteor. Soc., 137, 1117-1130, doi:10.1002/Qj.777, 2011.

Kandler, K., Schutz, L., Deutscher, C., Ebert, M., Hofmann, H., Jäckel, S., Jaenicke, R., Knippertz, P., Lieke, K., Massling, A., Petzold, A., Schladitz, A., Weinzierl, B., Wiedensohler, A., Zorn, S., and Weinbruch, S.: Size distribution, mass concentration, chemical and mineralogical composition and derived optical parameters of the boundary layer aerosol at Tinfou, Morocco, during SAMUM 2006, Tellus B, 61, 32-50, doi:10.1111/j.16000889.2008.00385.x, 2009.

Karyampudi, V. M., Palm, S. P., Reagen, J. A., Fang, H., Grant, W. B., Hoff, R. M., Moulin, C., Pierce, H. F., Torres, O., Browell, E. V., and Melfi, S. H.: Validation of the Saharan dust plume conceptual model using lidar, Meteosat, and ECMWF data, B. Am. Meteorol. Soc., 80, 1045-1075, 1999.

Kim, D., Chin, M., Yu, H., Eck, T. F., Sinyuk, A., Smirnov, A., and Holben, B.: Dust optical properties over North Africa and Arabian Peninsula derived from the AERONET dataset, Atmos. Chem. Phys., 11, 10733-10741, doi:10.5194/acp-1110733-2011, 2011.

Kocha, C., Flamant, C., Parker, D. J., Marnas, F., Garcia-Carreras, L., Rosenberg, P., Ryder, C. L., Marsham, J., Lafore, J.-P., Knippertz, P., and Tulet, P.: Characteristics and evolution over the Sahara of a cold-pool generated by Atlas convection, in preparation, $2013 a$.
Kocha, C., Flamant, C., Parker, D. J., Marnas, F., Garcia-Carreras, L., Rosenberg, P., Ryder, C. L., Marsham, J., Lafore, J.-P., Knippertz, P., and Tulet, P.: How a dusty density current can change the evolution of the Saharan Boundary Layer?, in preparation, $2013 b$.

Kok, J. F.: A scaling theory for the size distribution of emitted dust aerosols suggests climate models underestimate the size of the global dust cycle, P. Natl. Acad. Sci. USA, 108, 1016-1021, doi:10.1073/pnas.1014798108, 2011a.

Kok, J. F.: Does the size distribution of mineral dust aerosols depend on the wind speed at emission?, Atmos. Chem. Phys., 11, 1014910156, doi:10.5194/acp-11-10149-2011, 2011 b.

Lack, D. A., Cappa, C. D., Covert, D. S., Baynard, T., Massoli, P., Sierau, B., Bates, T. S., Quinn, P. K., Lovejoy, E. R., and Ravishankara, A. R.: Bias in filter-based aerosol light absorption measurements due to organic aerosol loading: Evidence from ambient measurements, Aerosol Sci. Technol., 42, 1033-1041, doi:10.1080/02786820802389277, 2008.

Lavaysse, C., Chaboureau, J. P., and Flamant, C.: Dust impact on the West African heat low in summertime, Q. J. Roy. Meteor. Soc., 137, 1227-1240, doi:10.1002/Qj.844, 2011.

Liao, H. and Seinfeld, J. H.: Radiative forcing by mineral dust aerosols: sensitivity to key variables, J. Geophys. Res.-Atmos., 103, 31637-31645, 1998.

Liu, Z. Y., Omar, A., Vaughan, M., Hair, J., Kittaka, C., Hu, Y. X., Powell, K., Trepte, C., Winker, D., Hostetler, C., Ferrare, R., and Pierce, R.: CALIPSO lidar observations of the optical properties of Saharan dust: A case study of long-range transport, J. Geophys. Res.-Atmos., 113, D07207, doi:10.1029/2007jd008878, 2008.

Maring, H., Savoie, D. L., Izaguirre, M. A., Custals, L., and Reid, J. S.: Mineral dust aerosol size distribution change during atmospheric transport, J. Geophys. Res.-Atmos., 108, 8592, doi:10.1029/2002jd002536, 2003.

Markwardt, C. B.: Non-Linear Least Squares Fitting in IDL with MPFIT, ASP Conference Series ADASS XVIII, Quebec, Canada, 2008, 251-254, 2008.

Marsham, J., Hobby, M., Allen, C., J, B., Bart, M., Brooks, B., Cavazos-Guerra, C., Engelstaedter, S., Gascoyne, M., McQuaid, J., O'Learly, A., Ouchene, B., Ouladichir, A., Parker, D., Saci, A., Salah-Ferroudj, M., Todd, M., and Washington, R.: Meteorology and dust in the central Sahara: Observations from Fennec superiste-1 during the June 2011 Intensive Observation Period, submitted to J. Geophys. Res.-Atmos., 2013.

Marsham, J. H., Knippertz, P., Dixon, N. S., Parker, D. J., and Lister, G. M. S.: The importance of the representation of deep convection for modeled dust-generating winds over West Africa during summer, Geophys. Res. Lett., 38, L16803, doi:10.1029/2011GL048368, 2011.

Matsuki, A., Quennehen, B., Schwarzenboeck, A., Crumeyrolle, S., Venzac, H., Laj, P., and Gomes, L.: Temporal and vertical variations of aerosol physical and chemical properties over West Africa: AMMA aircraft campaign in summer 2006, Atmos. Chem. Phys., 10, 8437-8451, doi:10.5194/acp-10-84372010, 2010.

McConnell, C. L., Highwood, E. J., Coe, H., Formenti, P., Anderson, B., Osborne, S., Nava, S., Desboeufs, K., Chen, G., and Harrison, M. A. J.: Seasonal variations of the physical and optical characteristics of Saharan dust: Results from the Dust Outflow 
and Deposition to the Ocean (DODO) experiment, J. Geophys. Res.-Atmos., 113, D14S05, doi:10.1029/2007jd009606, 2008.

McConnell, C. L., Formenti, P., Highwood, E. J., and Harrison, M. A. J.: Using aircraft measurements to determine the refractive index of Saharan dust during the DODO Experiments, Atmos. Chem. Phys., 10, 3081-3098, doi:10.5194/acp-10-30812010, 2010.

McQuaid, J., Ryder, C. L., Flamant, C., Washington, R., Brindley, H., Highwood, E. J., Marsham, J., Parker, D. J., Todd, M., Allen, C., Banks, J. R., Bourdon, A., Brooke, J., Cavazos, C., Dorsey, J., Engelstaedter, S., Formenti, P., Garcia-Carreras, L., Kocha, C., Marenco, F., Rosenberg, P., Sodemann, H., Trembath, J., Turnbull, K., and Woolley, A.: Overview and Highlights of Airborne Observations over the Sahara during Fennec 2011 and 2012, in preparation, 2013.

Müller, D., Weinzierl, B., Petzold, A., Kandler, K., Ansmann, A., Müller, T., Tesche, M., Freudenthaler, V., Esselborn, M., Heese, B., Althausen, D., Schladitz, A., Otto, S., and Knippertz, P.: Mineral dust observed with AERONET Sun photometer, Raman lidar, and in situ instruments during SAMUM 2006: Shapeindependent particle properties, J. Geophys. Res.-Atmos., 115, D07202, doi:10.1029/2009jd012520, 2010.

Müller, D., Lee, K. H., Gasteiger, J., Tesche, M., Weinzierl, B., Kandler, K., Müller, T., Toledano, C., Otto, S., Althausen, D., and Ansmann, A.: Comparison of optical and microphysical properties of pure Saharan mineral dust observed with AERONET Sun photometer, Raman lidar, and in situ instruments during SAMUM 2006, J. Geophys. Res.-Atmos., 117, D07211, doi:10.1029/2011jd016825, 2012.

Muyshondt, A., McFarland, A. R., and Anand, N. K.: Deposition of aerosol particles in contraction fittings, Aerosol Sci. Technol., 24, 205-216, 1996.

Ogren, J. A.: Comment on oCalibration and Intercomparison of Filter-Based Measurements of Visible Light Absorption by Aerosolso, Aerosol Sci. Technol., 44, 589-591, doi:10.1080/02786826.2010.482111, 2010.

Osborne, S. R., Johnson, B. T., Haywood, J. M., Baran, A. J., Harrison, M. A. J., and McConnell, C. L.: Physical and optical properties of mineral dust aerosol during the Dust and Biomassburning Experiment, J. Geophys. Res.-Atmos., 113, D00C03, doi:10.1029/2007jd009551, 2008.

Otto, S., Bierwirth, E., Weinzierl, B., Kandler, K., Esselborn, M., Tesche, M., Schladitz, A., Wendisch, M., and Trautmann, T.: Solar radiative effects of a Saharan dust plume observed during SAMUM assuming spheroidal model particles, Tellus B, 61, 270296, doi:10.1111/j.1600-0889.2008.00389.x, 2009.

Perlwitz, J. and Miller, R. L.: Cloud cover increase with increasing aerosol absorptivity: A counterexample to the conventional semidirect aerosol effect, J. Geophys. Res.-Atmos., 115, D08203, doi:10.1029/2009jd012637, 2010.

Petzold, A., Rasp, K., Weinzierl, B., Esselborn, M., Hamburger, T., Dörnbrack, A., Kandler, K., Schütz, L., Knippertz, P., Fiebig, M., and Virkkula, A.: Saharan dust absorption and refractive index from aircraft-based observations during SAMUM 2006, Tellus B, 61, 118-130, doi:10.1111/j.1600-0889.2008.00383.x, 2009.

Petzold, A., Veira, A., Mund, S., Esselborn, M., Kiemle, C., Weinzierl, B., Hamburger, T., Ehret, G., Lieke, K., and Kandler, K.: Mixing of mineral dust with urban pollution aerosol over Dakar (Senegal): impact on dust physico-chemical and ra- diative properties, Tellus B, 63, 619-634, doi:10.1111/j.16000889.2011.00547.x, 2011.

Piu, D. Y. H., Romnay Novas, F., and Liu, B. Y. H.: Experimental study of particle deposition in bends of circular cross section, Aerosol Sci. Technol., 7, 301-315, 1987.

Quirantes, A., Olmo, F. J., Lyamani, H., and Alados-Arboledas, L.: Correction factors for a total scatter/backscatter nephelometer, J. Quant. Spectrosc. Ra., 109, 1496-1503, doi:10.1016/j.jqsrt.2007.12.014, 2008.

Randles, C., Kinne, S., Myhre, G., Schulz, M., Stier, P., Fischer, J., Doppler, L., Highwood, E., Ryder, C., Harris, Huttunen, J., Ma, Y., Pinker, R. T., Mayer, B., Neubauer, D., Hitzenberger, R., Oreopoulos, L., Lee, D., Pitari, G., Genova, G. D., Rose, F. G., Kato, S., Rumbold, S. T., Vardavas, Hatzianastassiou, N., Matsoukas, C., Yu, H., Zhang, F., Zhang, H., and Lu, P.: Intercomparison of shortwave radiative transfer schemes in global aerosol modeling: Results from the AeroCom Radiative Transfer Experiment, Atmos. Chem. Phys. Discuss., 12, 32631-32706, doi:10.5194/acpd-12-32631-2012, 2012.

Redelsperger, J. L., Thorncroft, C. D., Diedhiou, A., Lebel, T., Parker, D. J., and Polcher, J.: African monsoon multidisciplinary analysis - An international research project and field campaign, B. Am. Meteorol. Soc., 87, 1739-1746, doi:10.1175/Bams-8712-1739, 2006.

Reid, J. S., Jonsson, H. H., Maring, H. B., Smirnov, A., Savoie, D. L., Cliff, S. S., Reid, E. A., Livingston, J. M., Meier, M. M., Dubovik, O., and Tsay, S. C.: Comparison of size and morphological measurements of coarse mode dust particles from Africa, J. Geophys. Res.-Atmos., 108, 8593, doi:10.1029/2002jd002485, 2003.

Reid, J. S. and Maring, H. B.: Foreword to special section on the Puerto Rico Dust Experiment (PRIDE), J. Geophys. Res.Atmos., 108, 8585, doi:10.1029/2003jd003510, 2003.

Reid, J. S., Reid, E. A., Walker, A., Piketh, S., Cliff, S., Al Mandoos, A., Tsay, S. C., and Eck, T. F.: Dynamics of southwest Asian dust particle size characteristics with implications for global dust research, J. Geophys. Res.-Atmos., 113, D14212, doi:10.1029/2007jd009752, 2008.

Richardson, M. S., DeMott, P. J., Kreidenweis, S. M., Cziczo, D. J., Dunlea, E. J., Jimenez, J. L., Thomson, D. S., Ashbaugh, L. L., Borys, R. D., Westphal, D. L., Casuccio, G. S., and Lersch, T. L.: Measurements of heterogeneous ice nuclei in the western United States in springtime and their relation to aerosol characteristics, J. Geophys. Res.-Atmos., 112, D02209, doi:10.1029/2006jd007500, 2007.

Rosenberg, P. D., Dean, A. R., Williams, P. I., Dorsey, J. R., Minikin, A., Pickering, M. A., and Petzold, A.: Particle sizing calibration with refractive index correction for light scattering optical particle counters and impacts upon PCASP and CDP data collected during the Fennec campaign, Atmos. Meas. Tech., 5, 1147-1163, doi:10.5194/amt-5-1147-2012, 2012.

Schepanski, K., Tegen, I., Laurent, B., Heinold, B., and Macke, A.: A new Saharan dust source activation frequency map derived from MSG-SEVIRI IR-channels, Geophys. Res. Lett., 34, L18803, doi:10.1029/2007g1030168, 2007.

Schepanski, K., Tegen, I., and Macke, A.: Saharan dust transport and deposition towards the tropical northern Atlantic, Atmos. Chem. Phys., 9, 1173-1189, doi:10.5194/acp-9-1173-2009, 2009. 
Seinfeld, J. H. and Pandis, S. N.: Properties of the Atmospheric Aerosol, in: Atmospheric Chemistry and Physics: From Air Pollution to Climate Change, 2nd ed., John Wiley \& Sons, New Jersey, USA, 362-365, 2006.

Shao, Y. P., Wyrwoll, K. H., Chappell, A., Huang, J. P., Lin, Z. H., McTainsh, G. H., Mikami, M., Tanaka, T. Y., Wang, X. L., and Yoon, S.: Dust cycle: An emerging core theme in Earth system science, Aeolian Res., 2, 181-204, doi:10.1016/j.aeolia.2011.02.001, 2011.

Sodemann, H., Lai, M., Knippertz, P., Bart, M., Marenco, F., McQuaid, J., Rosenberg, P., and Ryder, C.: Dust emission by a mesoscale convective system during the Fennec/LADUNEX field campaign simulated with a Lagrangian dust transport model, in preparation, 2013.

Todd, M., Cavazos-Guerra, C., Wang, Y., Washington, R., Allen, C., Engelstaedter, S., Marsham, J. H., Garcia-Carreras, L., Hobby, M., Bart, M., Parker, D. J., Brooks, B., Gasgoyne, M., Bechir, Gandega, R., Traore, Dieh, A., Janvier, Martins, V. J., Lima, A., Flamant, C., Kocha, C., and Podvin, T.: Meteorological and dust aerosol conditions over the Western Saharan region observed at Fennec supersite-2 during the Intensive Observation Period June 2011, submitted to J. Geophys. Res., 2013.

Trembath, J., Bart, M., and Brooke, J.: FAAM Technical Note: Efficiencies of modified Rosemount housings for sampling aerosol on a fast atmospheric research aircraft, Facility for Airborne Atmospheric Measurements, FAAM, Cranfield, UK, http://www.faam.ac.uk/index.php/component/docman/cat_ view/140-science-instruments (last access: 7 Januar 2013), 2012.

Turnbull, K.: PSAP Corrections, Met Office, OBR, UK Met Office, Exeter, UK, Technical Note No. 80, http://www.faam.ac.uk/index.php/component/docman/cat_view/ 140-science-instruments (last access: 7 Januar 2013), 2010.

Turnbull, K., Johnson, B., Marenco, F., Haywood, J., Minikin, A., Weinzierl, B., Schlager, H., Schumann, U., Leadbetter, S., and Woolley, A.: A case study of observations of volcanic ash from the Eyjafjallajokull eruption: 1. In situ airborne observations, J. Geophys. Res.-Atmos., 117, D00u12, doi:10.1029/2011jd016688, 2012.
Wagner, R., Ajtai, T., Kandler, K., Lieke, K., Linke, C., Müller, T., Schnaiter, M., and Vragel, M.: Complex refractive indices of Saharan dust samples at visible and near UV wavelengths: a laboratory study, Atmos. Chem. Phys., 12, 2491-2512, doi:10.5194/acp-12-2491-2012, 2012.

Washington, R., Todd, M., Middleton, N. J., and Goudie, A. S.: Dust-storm source areas determined by the total ozone monitoring spectrometer and surface observations, Ann. Assoc. Am. Geogr., 93, 297-313, 2003.

Washington, R., Flamant, C., Parker, D. J., Marsham, J., McQuaid, J. B., Brindley, H., Todd, M., Highwood, E. J., Chaboureau, J.P., Kocha, C., Bechir, M., Saci, A., and Ryder, C. L.: Fennec The Saharan Climate System, submitted to CLIVAR Exchanges, 2013.

Weinzierl, B., Petzold, A., Esselborn, M., Wirth, M., Rasp, K., Kandler, K., Schütz, L., Koepke, P., and Fiebig, M.: Airborne measurements of dust layer properties, particle size distribution and mixing state of Saharan dust during SAMUM 2006, Tellus B, 61 , 96-117, doi:10.1111/j.1600-0889.2008.00392.x, 2009.

Weinzierl, B., Sauer, D., Esselborn, M., Petzold, A., Veira, A., Rose, M., Mund, S., Wirth, M., Ansmann, A., Tesche, M., Gross, S., and Freudenthaler, V.: Microphysical and optical properties of dust and tropical biomass burning aerosol layers in the Cape Verde region-an overview of the airborne in situ and lidar measurements during SAMUM-2, Tellus B, 63, 589-618, doi:10.1111/j.1600-0889.2011.00566.x, 2011.

Wilson, J. C., Lafleur, B. G., Hilbert, H., Seebaugh, W. R., Fox, J., Gesler, D. W., Brock, C. A., Huebert, B. J., and Mullen, J.: Function and performance of a low turbulence inlet for sampling supermicron particles from aircraft platforms, Aerosol Sci. Technol., 38, 790-802, doi:10.1080/027868290500841, 2004. 